\title{
Seismic Performance of Base-Isolated Precast Concrete Shear Wall Structure with AHW Connections
}

\author{
Wei Wang $\mathbb{D}^{1}{ }^{1}$ Aiqun Li, ${ }^{2,3}$ and Xingxing Wang ${ }^{1}$ \\ ${ }^{1}$ School of Architecture and Civil Engineering, Jiangsu University of Science and Technology, 2 Mengxi Road, Zhenjiang 212003, China \\ ${ }^{2}$ Beijing Advanced Innovation Center for Future Urban Design, Beijing University of Civil Engineering and Architecture, \\ 1 Zhanlanguan Road, Beijing 100044, China \\ ${ }^{3}$ School of Civil Engineering, Southeast University, 2 Sipailou, Nanjing 210096, China
}

Correspondence should be addressed to Wei Wang; wangweidimias@sina.com

Received 7 December 2017; Revised 25 February 2018; Accepted 7 March 2018; Published 22 April 2018

Academic Editor: Aly M. Aly

Copyright (C) 2018 Wei Wang et al. This is an open access article distributed under the Creative Commons Attribution License, which permits unrestricted use, distribution, and reproduction in any medium, provided the original work is properly cited.

\begin{abstract}
To improve the seismic performance and seismic reliability of precast concrete shear wall (PCSW) structure with improved assembly horizontal wall connections (AHW connections), base isolation technology was proposed to be applied in the PCSW structure. Two 1/4-scaled structure models using the improved AHW connections were constructed: a lead-rubber bearing (LRB) base-isolated PCSW structure model and a base-fixed PCSW structure model. Shaking table tests were conducted on these two models with three strong ground motions to assess the seismic performance of the structures. It was found that the improved AHW connections in the base-isolated PCSW structure are useful and effective and that they fulfil the requirements to be met by the connections to withstand an earthquake. In addition, the maximum absolute acceleration and base shear force of the base-isolated PCSW structure model were less than those of the base-fixed PCSW structure model, and the isolation effect on the absolute acceleration responses and base shear responses increased with increase in the intensity of ground motions. In a word, the seismic performance and seismic reliability of PCSW structures can be effectively improved using base isolation technology. After this investigation, the seismic responses of the base-isolated PCSW structure model were numerically simulated using OpenSees software. There was a reasonable agreement between the numerically simulated results and test results; thus, the numerical simulation method and analysis model used for the base-isolated PCSW structure model were verified.
\end{abstract}

\section{Introduction}

Cast-in-place concrete shear wall structures (CCSW structures) are widely used throughout the world for their high strength and stiffness. Unlike in the case of CCSW structures, part of the field work can be transferred to the plant in the case of precast concrete shear wall (PCSW) structures; this can save a large amount of labour, reduce material consumption, and shorten the time for construction projects. Thus, PCSW structures can support the development of industrialised construction $[1-6]$.

1.1. Horizontal Connection. Assembly wall connections are the key elements of PCSW structures, which consist of assembly vertical wall connections and assembly horizontal wall connections (AHW connections). Assembly vertical wall connections are normally employed as energy dissipation connections or emulation connections. However, reliable AHW connections can normally guarantee the normal function of the PCSW structures.

There are three methods of assembling the AHW connections in the PCSW structures: (a) splicing longitudinal rebars using sleeves or stirrups combined with high-strength mortar [7-9]; (b) tying together the horizontal connections using unbounded posttensioned (UPT) precast concrete wall plates $[2,10,11]$; (c) connecting the longitudinal rebars using bolted connections [12, 13]. Several studies [1, 8, 11] indicate that the required mechanical properties of the AHW connections can be achieved with the assembly connection methods mentioned above by adopting effective construction measures. 
There are some studies on the seismic performance of PCSW structures with UPT connections and sleeve connections combined with high-strength mortar. One such study $[5,6]$ presents shaking table tests and numerical analysis of the UPT wall structures. The results show that the UPT wall structures exhibit no residual deformation and show minimal damage during an earthquake. Some studies $[1,14]$ indicate that the seismic performance of the PCSW structure with AHW connection (i.e., longitudinal rebars spliced using sleeves combined with high-strength mortar) and the CCSW structure are similar. However, there has been little investigation on the seismic behaviour of PCSW structures with AHW connection using bolted connections.

1.2. Base Isolation Technology. Seismic isolation is a useful technology to reduce the seismic forces acting on structures. Base-isolated systems are effective because of their excellent energy dissipation characteristics and flexibility. Over the years, many studies have dealt with reliability analysis and reliability-based optimization of base-isolated systems including uncertainties such as isolation device properties and ground motion characteristics [15-17]. The results indicate that base isolation technology can improve the seismic reliability of structures subjected to earthquakes [18-20]. Lead-rubber bearing (LRB) is one of the most useful isolation devices in practice. During an earthquake, the LRBs dissipate most of the input earthquake energy. After the earthquake, because of the recentering capacity of the LRBs, the original position (corresponding to zero deformation) can be restored [21-23]. In recent years, LRBs have been extensively employed in structures to reduce the seismic effects because of their energy dissipation and recentering capacity [24, 25]. In addition, one such study [26] presents sensitivity analysis on mechanical characteristics of LRBs. The results show that the lead core radius is the dominant parameter in affecting LRBs' performance.

1.3. Scope of Present Study. As base isolation can reduce the seismic forces acting on the structures, the forces acting on the base-isolated structures are less than those on the base-fixed structures; accordingly, the forces acting on the AHW connections in the base-isolated PCSW structures are lower. In other words, the performance of the AHW connections can be improved in the base-isolated PCSW structures. However, there has been little study on the seismic properties of base-isolated PCSW structures with AHW connections.

An improved AHW connection for PCSW structures has been presented in literature [1], and shaking table tests, and numerical simulation have been performed to evaluate the seismic performance of a base-fixed PCSW structure with the improved AHW connections [1]. The tested results indicate that there will be some cracks in the AHW connection area of the PCSW structure with improved AHW connections during server earthquakes. In order to reduce the cracks in the AHW connection area of the PCSW structure, base isolation technology is proposed to be applied in the PCSW structure.
This paper presents the seismic properties of a baseisolated PCSW structure model with the improved AHW connections. To study the seismic performance and energy dissipation capacity of the base-isolated PCSW structures, two 1/4-scaled models of the PCSW structure were built: a base-isolated PCSW structure model and a base-fixed PCSW structure model. Shaking table tests of the two models were conducted, and the absolute acceleration responses and the displacement responses of the base-isolated PCSW structure model were measured to reveal the dynamic properties of the structure. In addition, the seismic behaviour of the improved AHW connections was studied. Finally, the acceleration responses in the fourth storey and shear force-displacement responses in the isolation storey of the base-isolated PCSW structure were numerically simulated using OpenSees software.

\section{Improved AHW Connection}

The improved AHW connection technology used to realize the horizontal connection of the precast shear wall is shown in Figure 1 [1]. Connection steel plates and bolts are used to make the AHW connection between the lower and upper wall plates. The assembly sequence of the improved AHW connection is as follows.

(1) Weld the longitudinal rebars to their corresponding connection steel plates (see Figure 1(a)).

(2) Before hoisting the precast wall plates, cast a layer of high-strength mortar on the top of the lower wall plate; during the hoisting of the precast wall plates, insert the connection steel plates of the lower wall plate into the reserved channels of the upper wall plate at bottom (see Figure 1(b)).

(3) Adjust the positions of the upper and lower wall plates to align the reserved bolt holes in the connection steel plates and wall plates, insert the bolts in the aligned holes, and tighten the nuts to complete the improved AHW connection (see Figure 1(c)).

\section{Description of the Experiment}

3.1. Test Specimens. A four-storey base-isolated PCSW structure prototype was designed according to the "code for design of concrete structures" (GB50010-2010) of China [27]. Then, two four-storey 1/4-scaled superstructure models of the baseisolated PCSW structure were constructed. The similitude coefficients of the model are presented in Table 1. One is mounted on four LRBs to form the base isolation model (denoted as Specimen A); the other is bolted to the shaking table to form the base-fixed structure model (denoted as Specimen B). The drawings and images of Specimens A and $B$ are shown in Figure 2 [1]. The scaled model of the superstructure has a dimension of $1400 \times 1400 \mathrm{~mm}$ in the plan view; the thickness of the shear walls is $35 \mathrm{~mm}$; the height of the storey is $750 \mathrm{~mm}$; and the cross section of the coupling beams is $100 \times 100 \mathrm{~mm}$.

Ready-mixed concrete was used for casting the structure. The design compressive strength of the concrete was $22 \mathrm{MPa}$. 


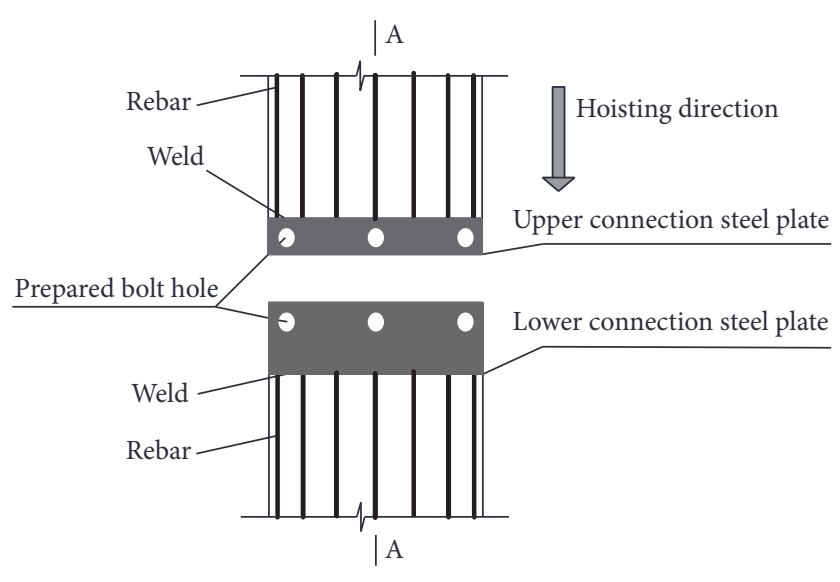

(a) Elevation

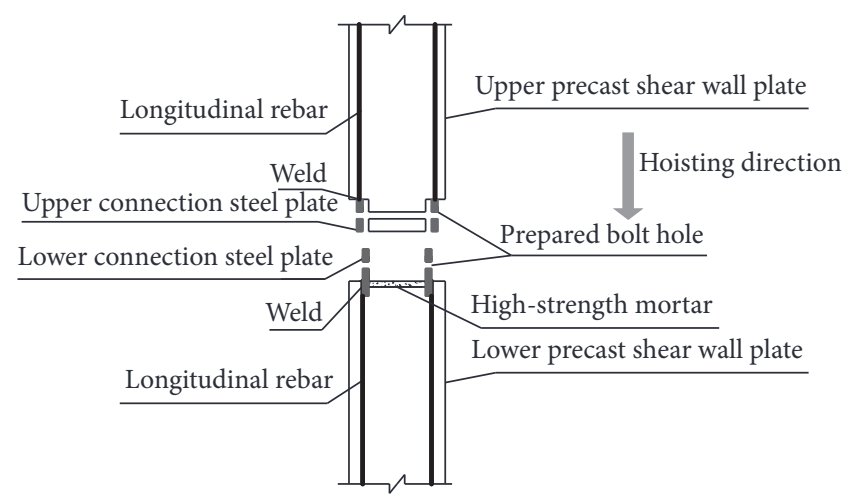

(b) Profile at section A-A

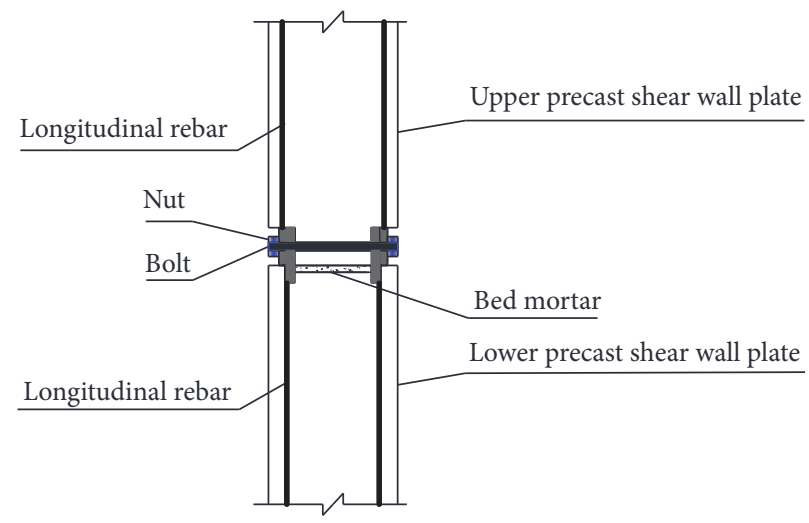

(c) Completed assembly

FIGURE 1: Improved AHW connection [1].

TABLE 1: Similitude coefficients.

\begin{tabular}{lc}
\hline Physical quantity & Ratio of similitude \\
\hline Mass & $S_{m}=1 / 16$ \\
Length & $S_{L}=1 / 4$ \\
Elastic modulus & $S_{E}=1$ \\
Acceleration & $S_{a}=1$ \\
Velocity & $S_{V}=1 / 2$ \\
Displacement & $S_{U}=1 / 4$ \\
Volume & $S_{V}=1 / 64$ \\
Time & $S_{t}=1 / 2$ \\
Frequency & $S_{f}=2$ \\
Force & $S_{F}=1 / 16$ \\
\hline
\end{tabular}

Table 2 presents the measured mechanical properties of the concrete.

Galvanized iron wires of $\phi 2.2$ were used for the longitudinal rebars and the transverse rebars in the shear walls and for the stirrups of the coupling beams and columns. Galvanized iron wires of $\phi 3$ were used for the longitudinal rebars of the beams in the $X$-direction. The measured mechanical properties of the galvanized iron wires are presented in Table 3.
TABLE 2: Measured mechanical properties of concrete.

\begin{tabular}{lc}
\hline Specimen & $\begin{array}{c}\text { Cubic compressive strength } \\
\text { fcu }(\mathrm{MPa})\end{array}$ \\
\hline 1st storey & 21.63 \\
2nd storey & 22.26 \\
3rd storey & 22.33 \\
4th storey & 21.10 \\
Isolation storey & 25.76 \\
\hline
\end{tabular}

Three types of connection steel plates were used; their dimensions are shown in Figure 3. The thickness of the steel plates is $3 \mathrm{~mm}$; the diameter of the bolt holes is $8.5 \mathrm{~mm}$; the $3 \mathrm{~mm}$ diameter holes are used for connecting the rebars. Figure 4 shows the improved AHW connections, transverse rebars, and longitudinal rebars used in the model.

The weights of the base beam, and the wall and floor of each storey are $2.48 \mathrm{t}, 0.35 \mathrm{t}$, and $0.25 \mathrm{t}$, respectively. Based on the scaling relation, the added mass of each storey is $0.6 \mathrm{t}$, and accordingly the total weight of the model is $7.06 \mathrm{t}$. Highstrength mortar was used to fix the gravity load trough to the structure. 

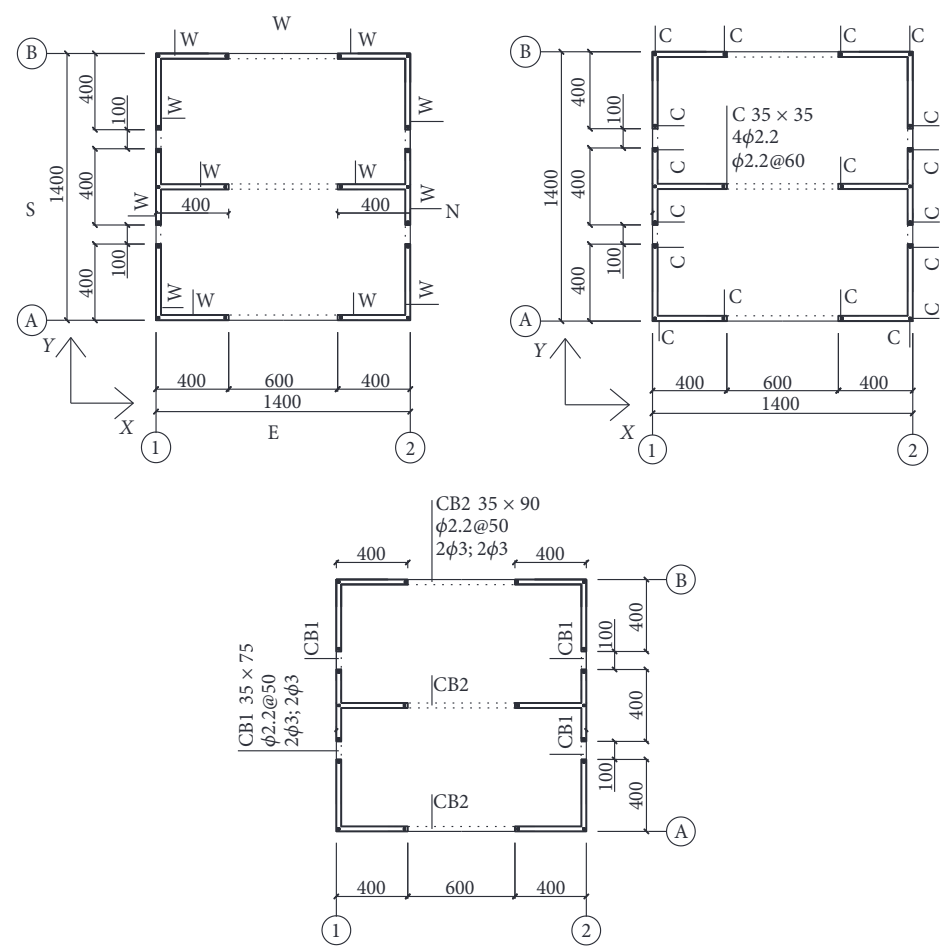

(a) Plan layout of a standard storey (unit: $\mathrm{mm}$ )
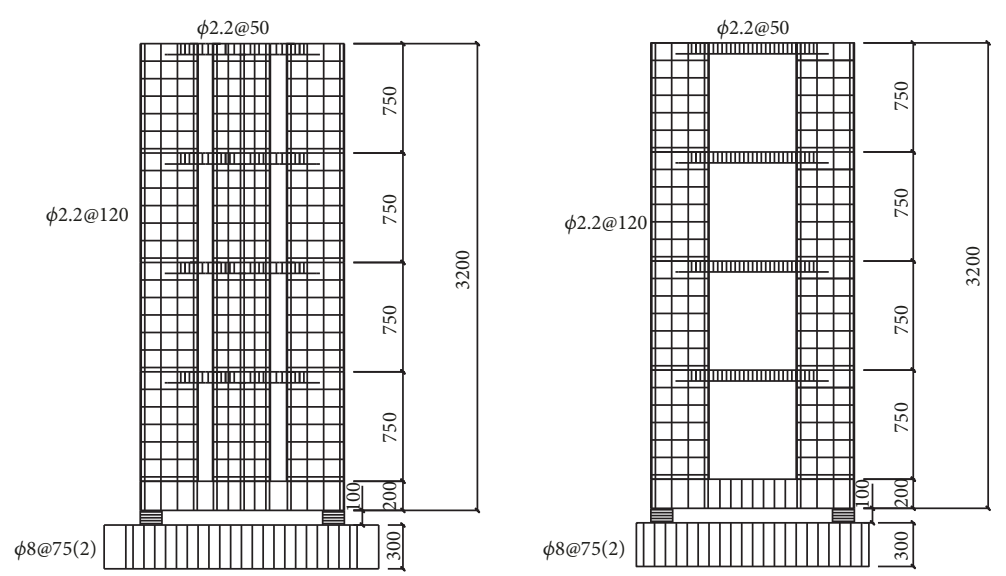

(b) Distribution of rebars in Specimen A (unit: $\mathrm{mm}$ )
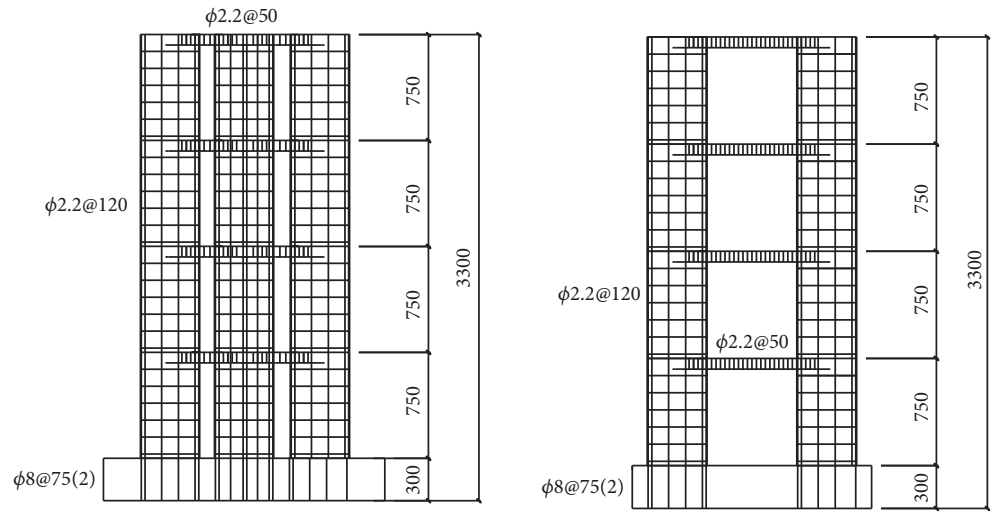

(c) Distribution of rebars in Specimen B (unit: $\mathrm{mm}$ )

Figure 2: Continued. 

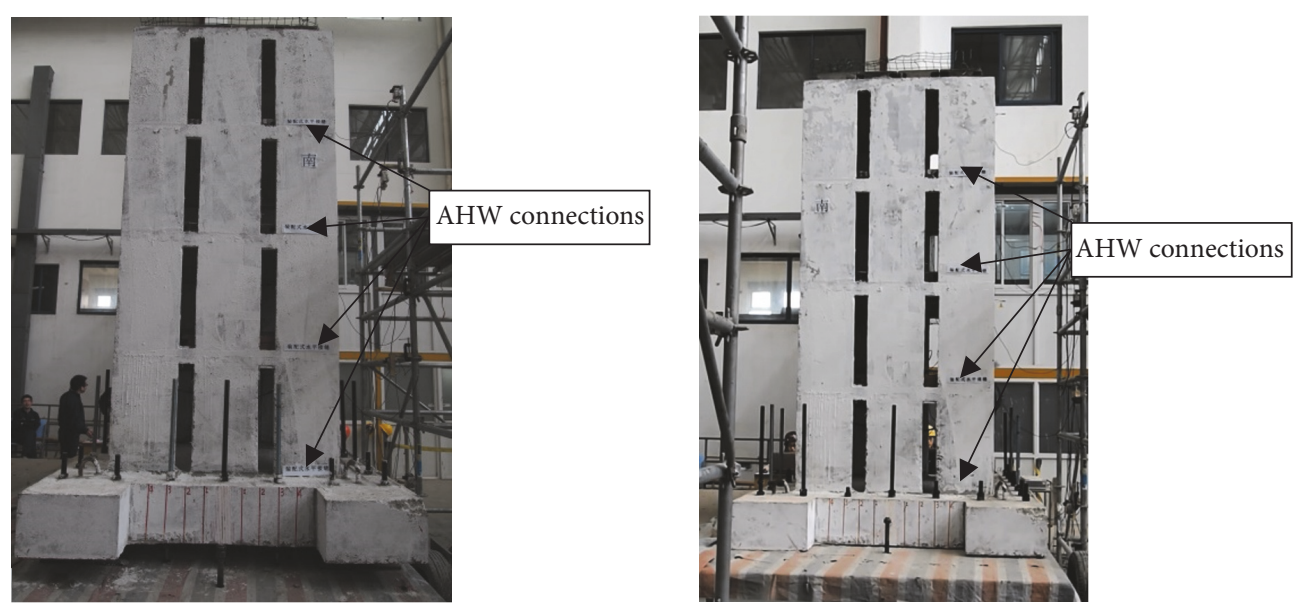

(d) Images of the installations of Specimens A and B

Figure 2: Test models and drawings.

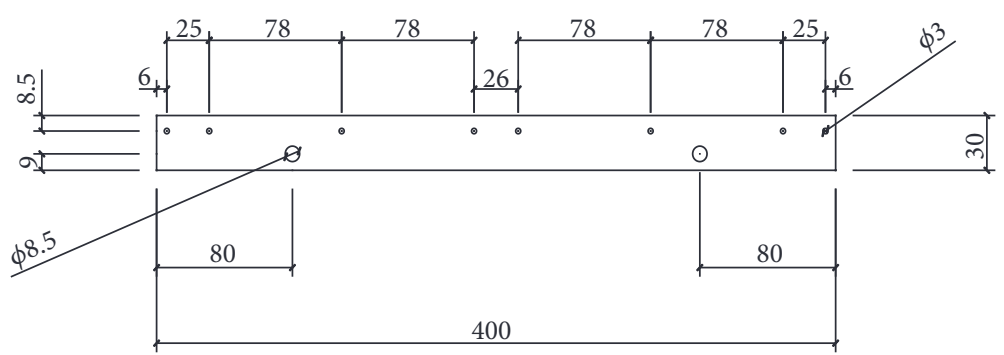

(a) Connection steel plate 1

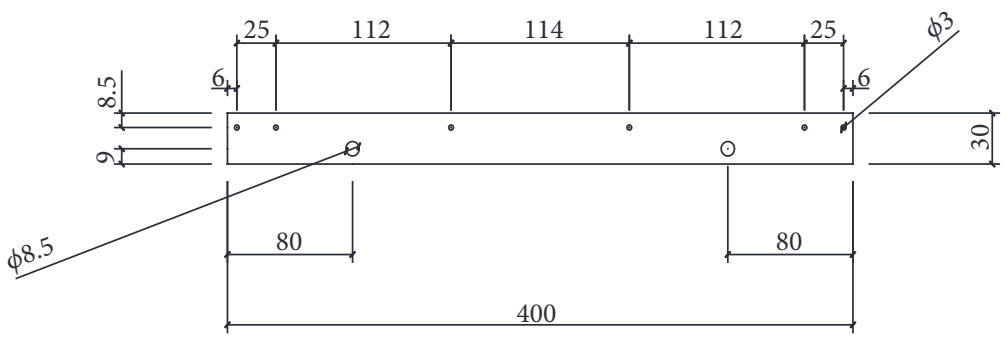

(b) Connection steel plate 2

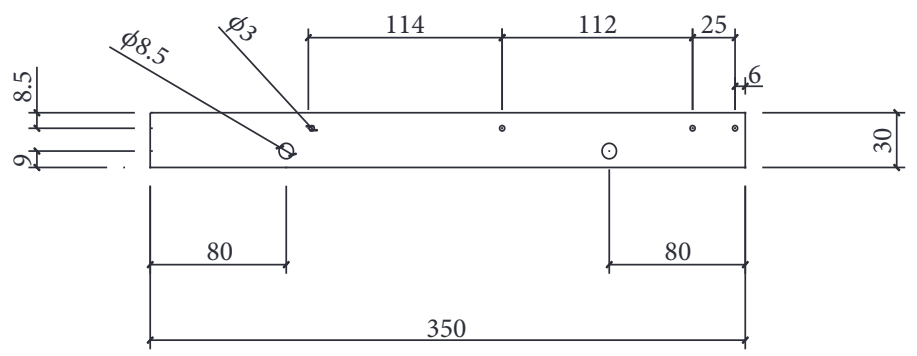

(c) Connection steel plate 3

FIGURE 3: Connection steel plates.

3.2. $L R B$. The $L R B s$ were formed by bonding 14 rubber layers and 13 shim layers alternatively (Figure 5). Table 4 summarizes the related parameters of the LRB. The mechanical properties of the LRBs were tested in the previous cyclic loading experiments. Figure 6 depicts the load-deformation curves of the LRB with $100 \%$ shear strain and $250 \%$ shear strain. It is observed that the lateral stiffness of the LRB shows approximately a bilinear mode. 
TABLE 3: Measured mechanical properties of galvanized iron wires.

\begin{tabular}{lccccc}
\hline Mechanical properties & $\begin{array}{c}\text { Diameter } \\
(\mathrm{mm})\end{array}$ & $\begin{array}{c}\text { Yield strength } \\
(\mathrm{MPa})\end{array}$ & $\begin{array}{c}\text { Tensile strength } \\
(\mathrm{MPa})\end{array}$ & $\begin{array}{c}\text { Elongation } \\
(\%)\end{array}$ & $\begin{array}{c}\text { Elastic modulus } \\
(\mathrm{MPa})\end{array}$ \\
\hline$\varphi 2.2$ & 2.2 & 241.6 & 330.6 & 19.7 & $1.8 \times 10^{5}$ \\
$\varphi 3$ & 3 & 235.7 & 319.6 & 20.2 & $1.8 \times 10^{5}$ \\
\hline
\end{tabular}

TABLE 4: Parameters of LRB.

\begin{tabular}{lccc}
\hline Scale parameter & Value & Force property parameter & Value \\
\hline Diameter $d_{0}(\mathrm{~mm})$ & 100 & Rubber shear modulus $G(\mathrm{~N} / \mathrm{mm} 2)$ & 0.4 \\
Rubber height $t_{r}(\mathrm{~mm})$ & 1.5 & Equivalent lateral stiffness $(\mathrm{kN} / \mathrm{mm})$ & 0.24 \\
Total rubber height $T_{r}(\mathrm{~mm})$ & 21 & Equivalent damping ratio & 0.11 \\
Shim height $t_{s}(\mathrm{~mm})$ & 4 & Post-yielding stiffness $(\mathrm{kN} / \mathrm{mm})$ & 0.13 \\
Total shim height $(\mathrm{mm})$ & 52 & Yield displacement $(\mathrm{mm})$ & 0.81 \\
Total height $(\mathrm{mm})$ & 89 & Initial lateral stiffness $(\mathrm{kN} / \mathrm{mm})$ & 1.21 \\
Diameter of lead $(\mathrm{mm})$ & 10 & & \\
\hline
\end{tabular}

Note. Mechanical parameters of the LRB with $100 \%$ shear strain.

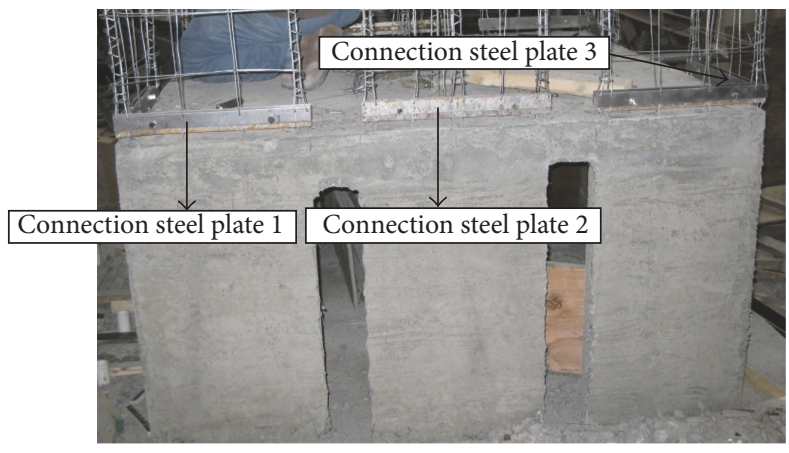

FIGURE 4: Construction of precast shear wall plates.

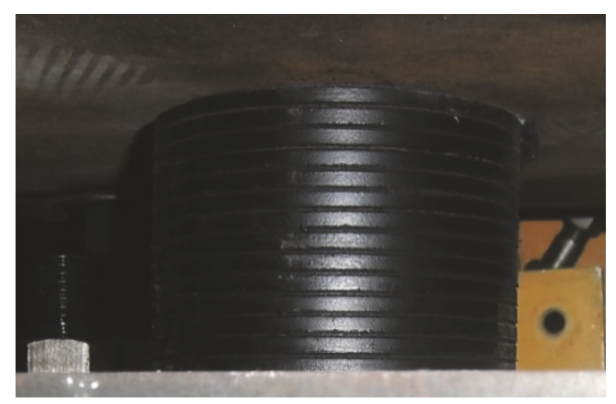

FIGURE 5: Image of LRB.

3.3. Test Procedure and Measurements. The dimension of the shaking table is $4 \times 6 \mathrm{~m}$; the maximum acceleration is $1.5 \mathrm{~g}$. During testing, the shaking table was driven in the $Y$ direction of the structure model.

Three ground motions were selected: the 1968 Castaic (CA) ground motion, the 1952 Taft (TA) ground motion, and a 2015 artificial (AR) ground motion; these motions are compatible with the response spectrum for soil type II in the "code for seismic design of buildings," GB 500112010 [27]. Figure 7 shows the acceleration time histories corresponding to the three ground motions with 100\% PGA scale, and Figure 8 shows the response spectrum curves of the acceleration time histories with a damping ratio of 5\% ((peak ground acceleration $(\mathrm{PGA})=400$ gal $)$ ).

To excite the specimens, ground motions with PGAs of 70 gal, 200 gal, and 400 gal were inputted in the shaking table, corresponding to the intensities of minor earthquakes, moderate earthquakes, and rare earthquakes, respectively, with a seismic fortification intensity of 8 degrees, as mentioned in the "code for seismic design of buildings" (GB50011-2010) [28]. Further, a white-noise ground motion (PGA = 25 gal) in the $Y$-direction was inputted in the shaking table to identify 


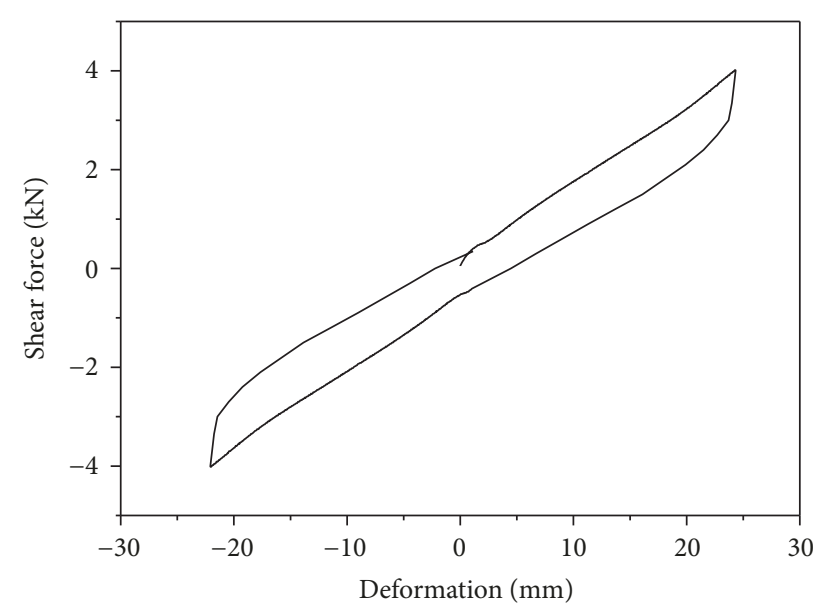

(a) $100 \%$ shear strain

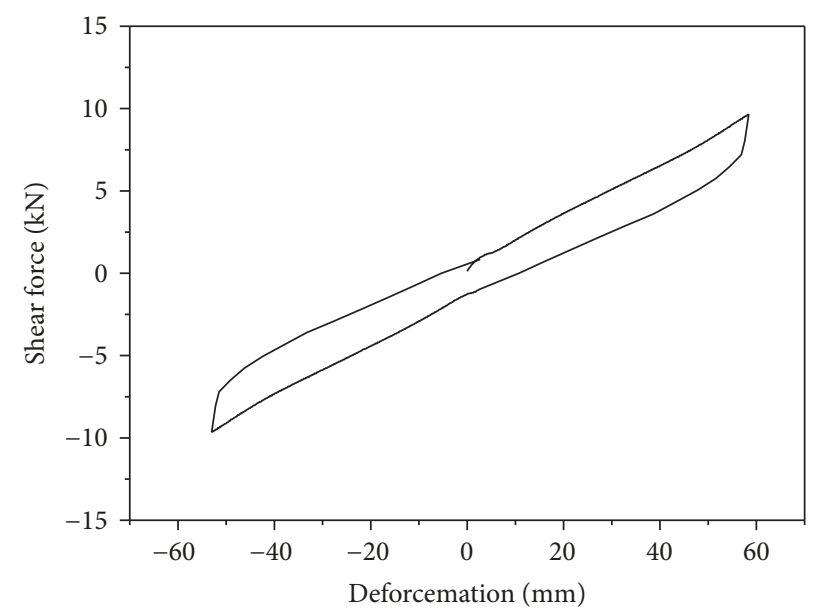

(b) $250 \%$ shear strain

FIgURE 6: Hysteresis curve of LRB.

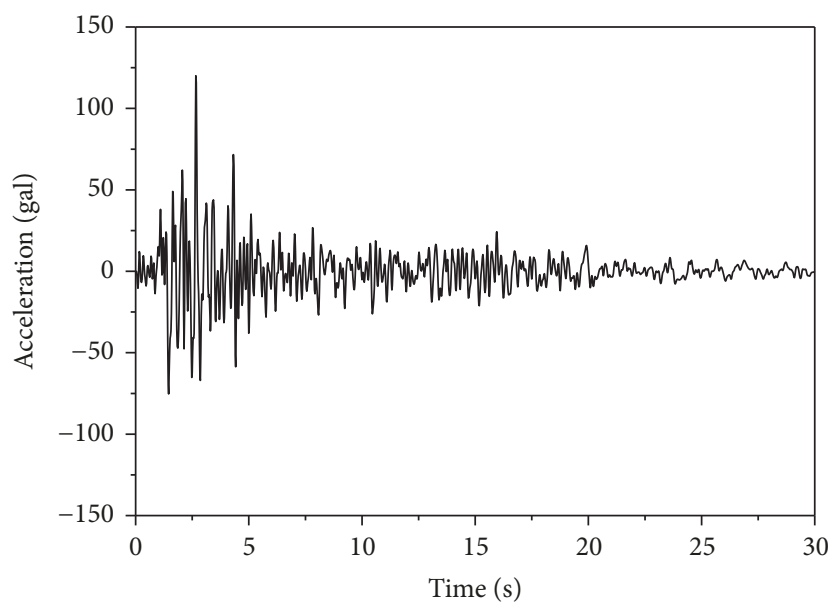

(a) CA1968

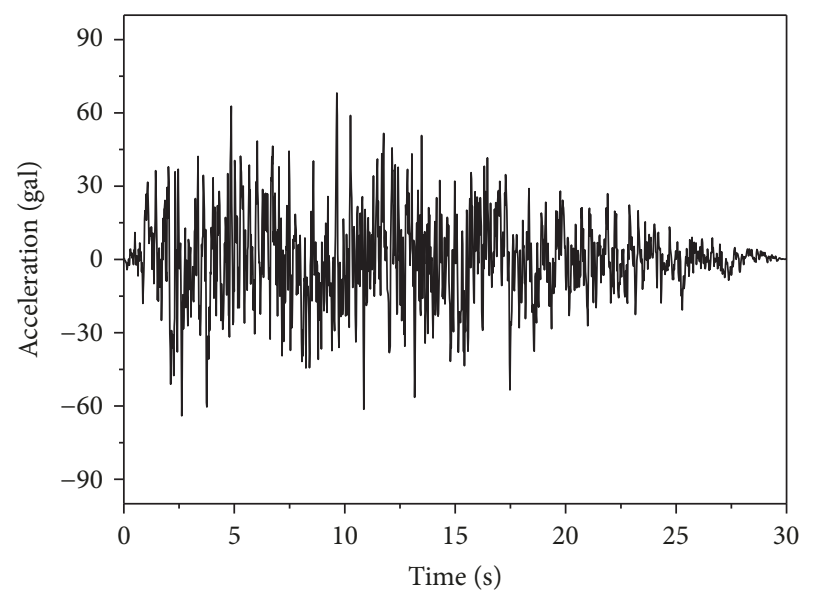

(b) AR2015

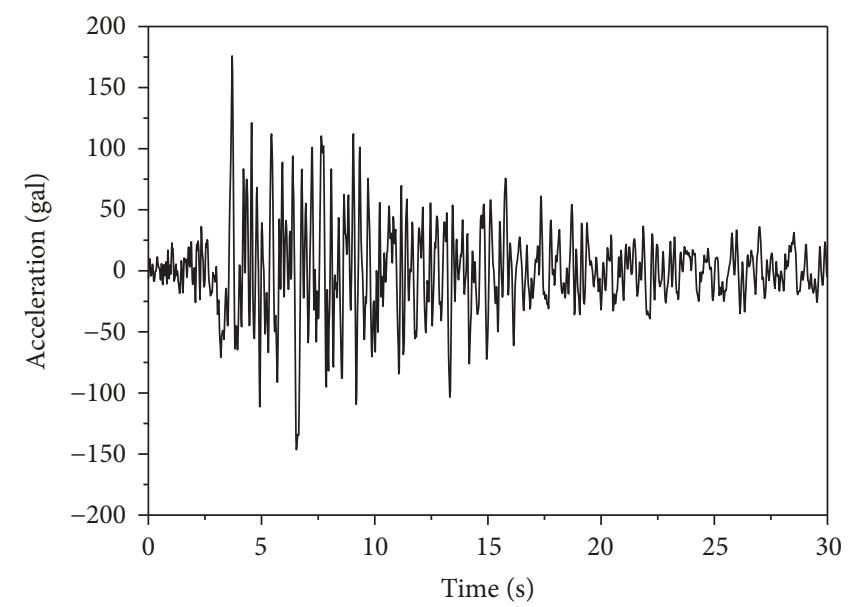

(c) TA 1952

FIGURE 7: Acceleration time histories of input ground motions. 


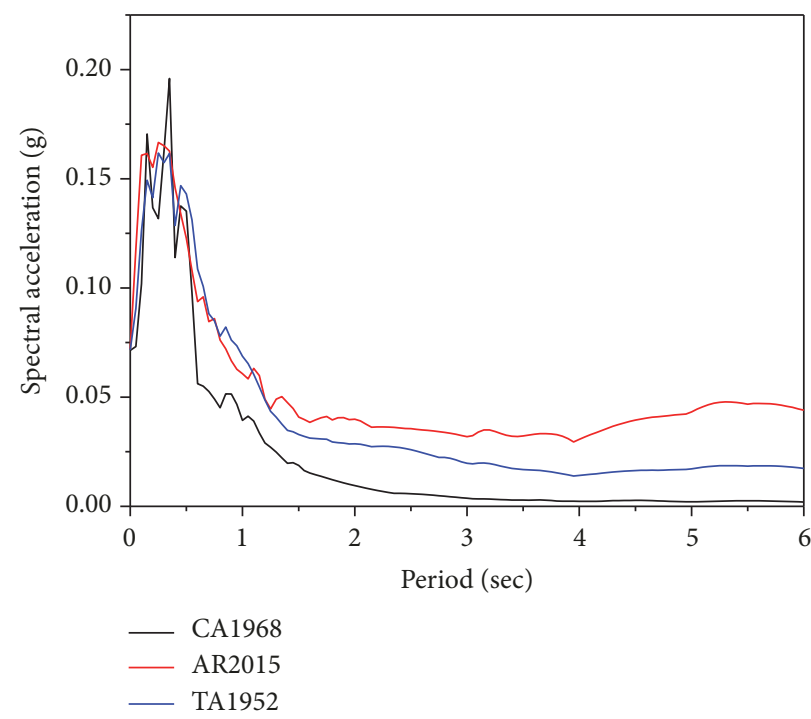

FIGURE 8: Response spectrum curves (damping ratio: 5\%) for input ground motions with PGA = 400 gal.

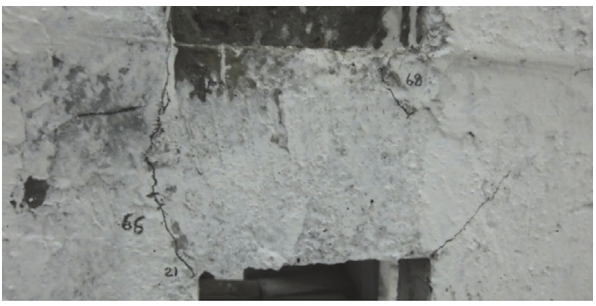

(a) Cracks in coupling beams

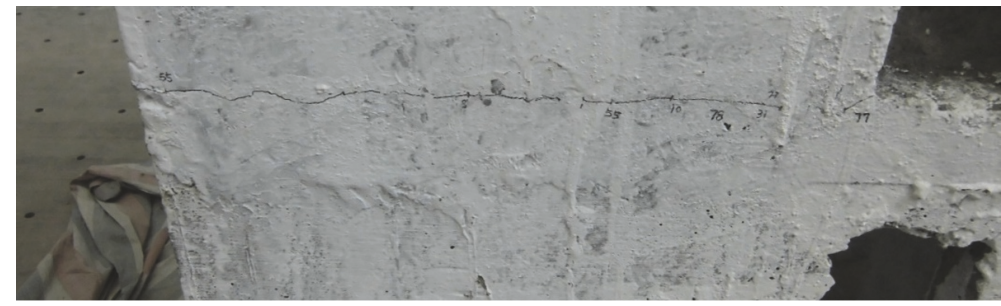

(b) Cracks in shear walls

FIgURE 9: Typical crack distribution in specimens.

TABLE 5: Test cases.

\begin{tabular}{lcc}
\hline Test case & Input excitation & PGA (gal) \\
\hline Rnd 1 & White noise & 25 \\
Test 1 & CA (1968), TA (1952), AR (2015) & 70 \\
Rnd 2 & White noise & 25 \\
Test 2 & CA (1968), TA (1952), AR (2015) & 200 \\
Rnd 3 & White noise & 25 \\
Test 3 & CA (1968), TA (1952), AR (2015) & 400 \\
Rnd 4 & White noise & 25 \\
\hline
\end{tabular}

the dynamic properties of the specimens. The test sequence is presented in Table 5.

The absolute acceleration and absolute displacements of the storeys of the test models were measured using piezoelectric accelerometers and displacement transducers, respectively.

\section{Experimental Results}

4.1. Test Phenomenon and Failure Modes. Typical cracks in the specimens are shown in Figure 9. It should be noted that the cracks in the structure model are relatively smaller than the whole structure, and it is difficult to see the crack marks in the whole structure photograph. Hence, the crack distribution in specimens is provided using pictures drawn by software CAD, as depicted in Figures 10 and 11 . They reflect the failure modes and seismic properties of the specimens. It can be seen that compared with Specimen B, Specimen A had less cracks in the coupling beams and shear walls, indicating that the isolation system had reduced the crack formation effectively. In addition, there was no crack in the AHW connection area in Specimen A, indicating that the reliability of the improved AHW connection and the safety of the PCSW structure can be ensured during earthquakes.

4.2. Modes. Figure 12 illustrates the first modes of Specimens $\mathrm{A}$ and $\mathrm{B}$ obtained from the experiment. It is observed that, in the first mode of Specimen A, the isolation storey undergoes deformation but the superstructure behaves as essentially rigid, while the first mode of Specimen B corresponds to a typical flexure type deformation. It can be seen that the modes of Specimens A and B before and after the tests are almost the same.

4.3. Dynamic Characteristics. The frequencies and damping ratios of the structure models were obtained from the transfer 


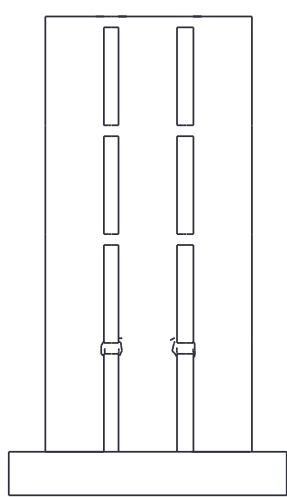

(a) South elevation

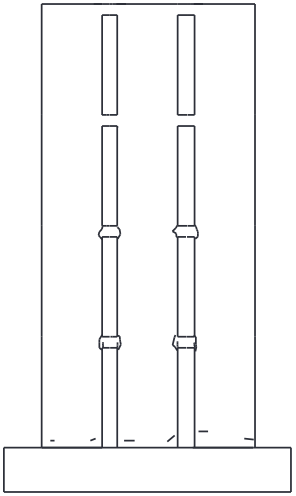

(a) South elevation

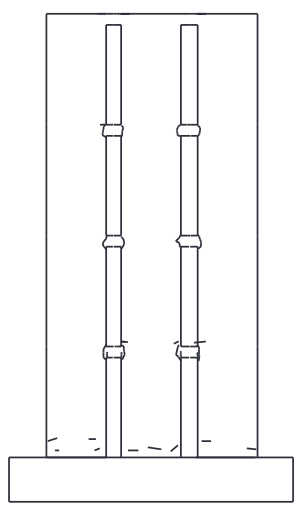

(a) South elevation

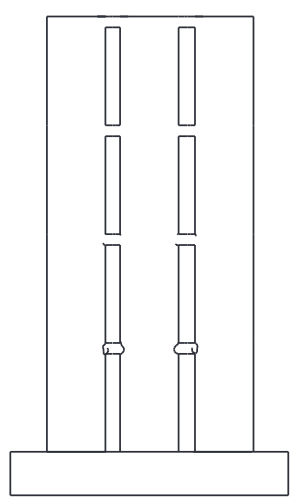

(b) North elevation

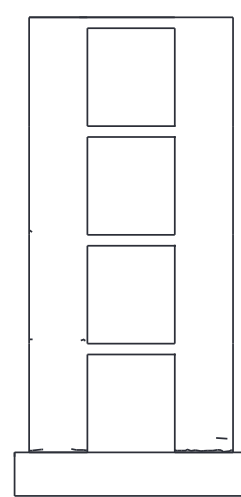

(c) West elevation

Crack distribution in Specimen A after Test 1

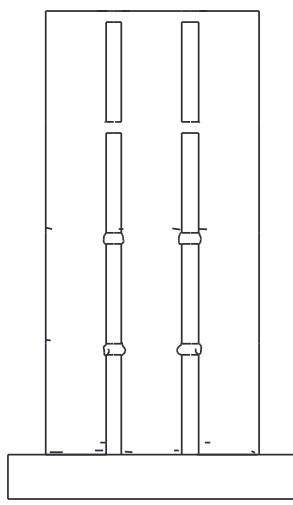

(b) North elevation

Crack distribution in Specimen A after Test 2

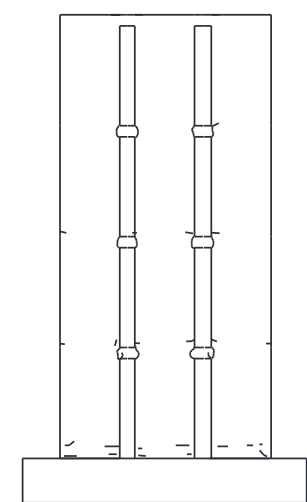

(b) North elevation

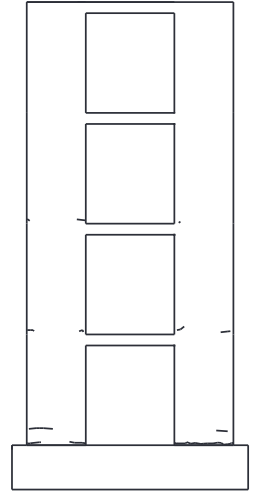

(c) West elevation

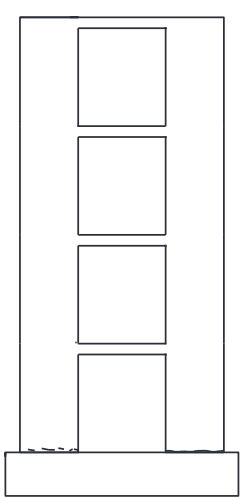

(d) East elevation

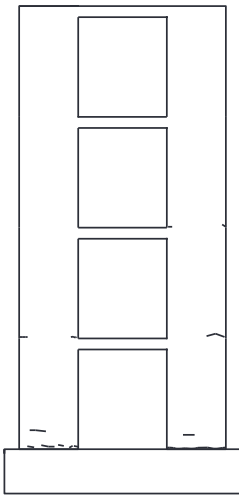

(d) East elevation

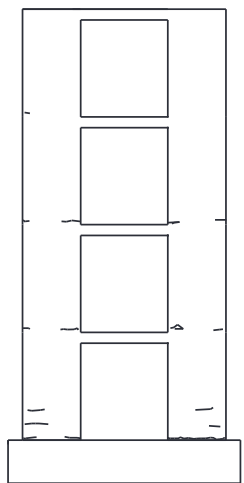

(c) West elevation

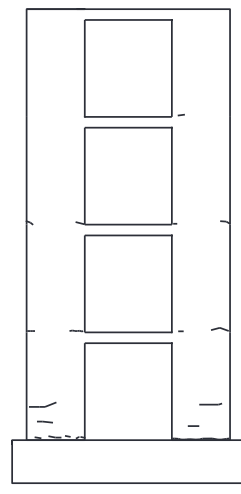

(d) East elevation

Crack distribution in Specimen A after Test 3

FIgURE 10: Crack distribution in Specimen A. 


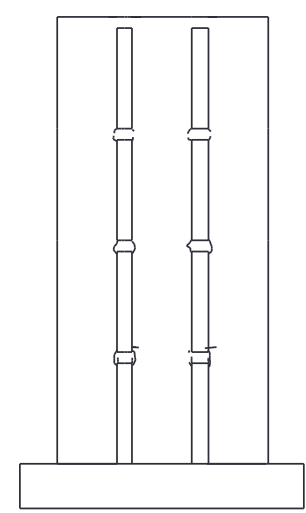

(a) South elevation

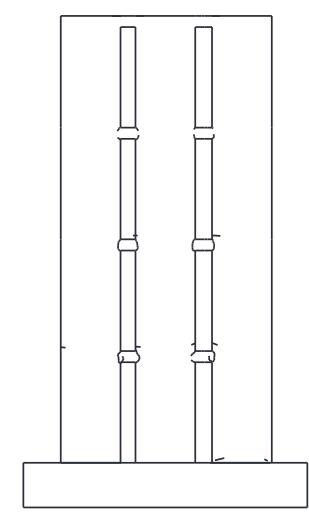

(b) North elevation

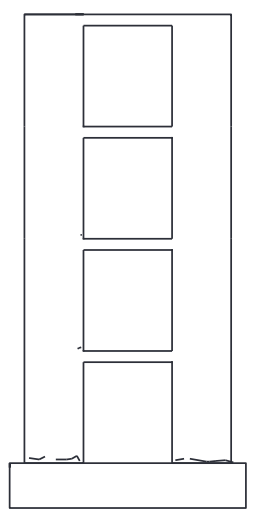

(c) West elevation

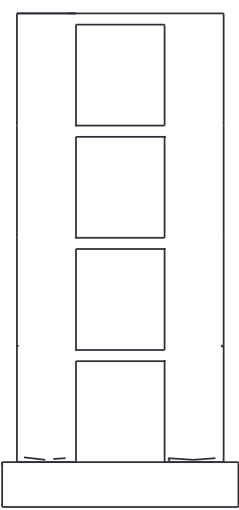

(d) East elevation

Crack distribution in Specimen B after Test 1

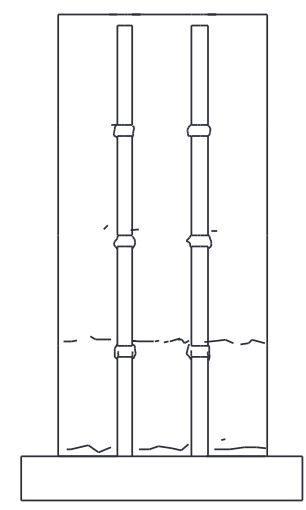

(a) South elevation

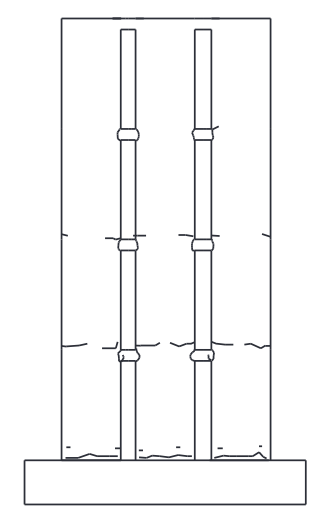

(b) North elevation

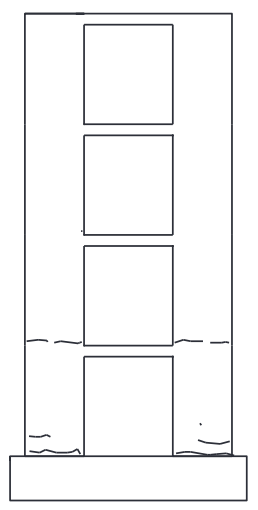

(c) West elevation

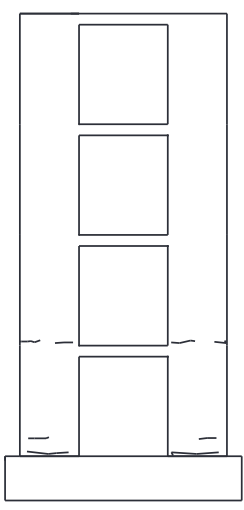

(d) East elevation

Crack distribution in Specimen B after Test 2

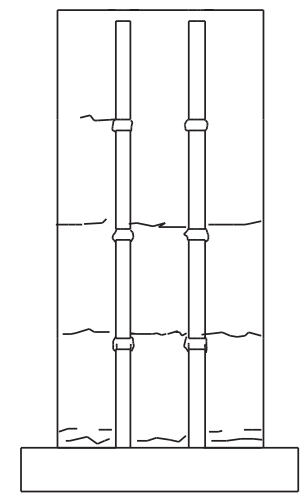

(a) South elevation

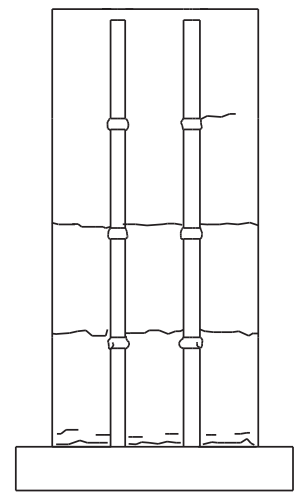

(b) North elevation

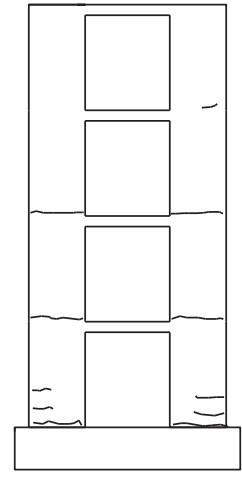

(c) West elevation

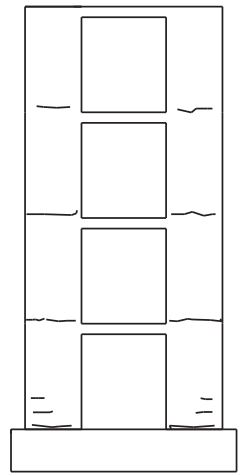

(d) East elevation

Crack distribution in Specimen B after Test 3

FIGURE 11: Crack distribution in Specimen B.

With increase in the input PGA, the damping ratio of Specimen A remains almost constant at approximately $16 \%$. When the input PGA is less than $70 \mathrm{gal}$, the damping ratio of Specimen B is approximately $3.6 \%$, and when the input PGA is $400 \mathrm{gal}$, the damping ratio increases to $7.54 \%$. Thus, the damping ratio of Specimen A is larger than that of Specimen B.

The frequency and the damping ratio of Specimen A are mainly decided by the LRBs. Because there are no significant changes in the mechanical properties of the LRBs during 


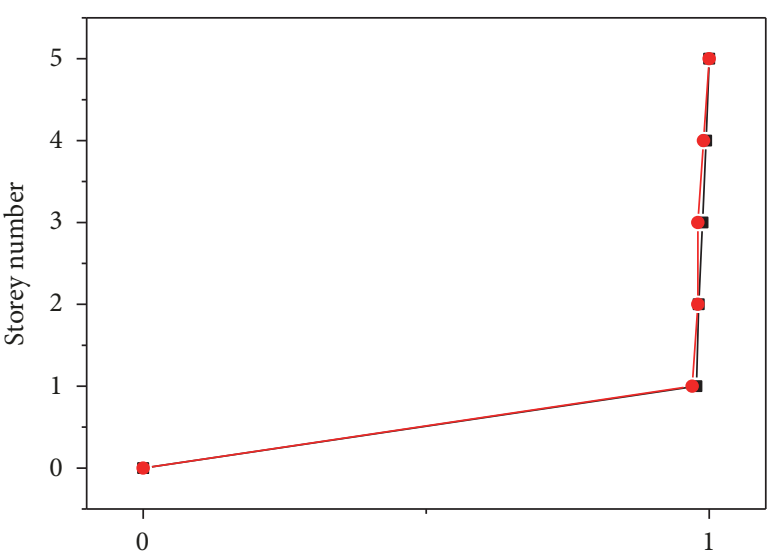

- - Before tests

- - After tests

(a) First modes of Specimen A

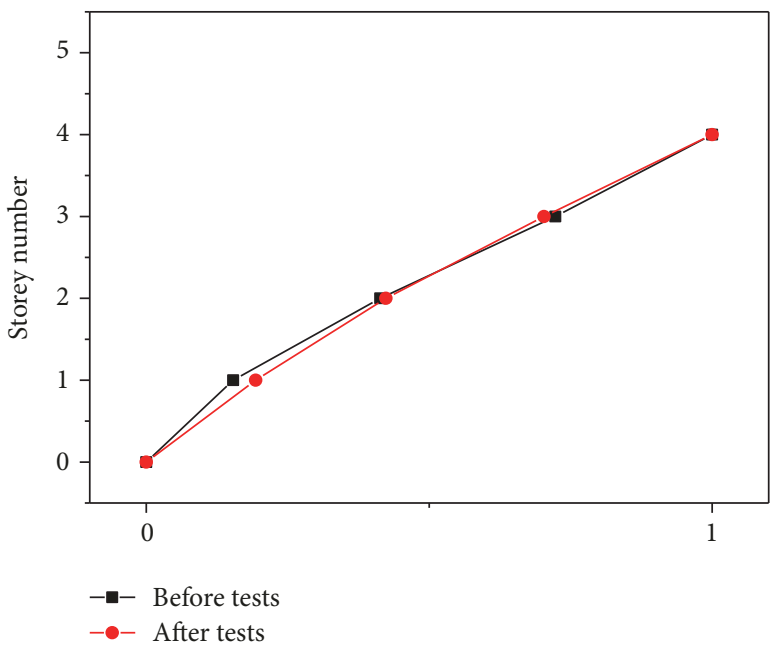

(b) First modes of Specimen B

FIGURE 12: Modes obtained from the experiment. Note. Storey number "0" corresponds to the isolation storey.

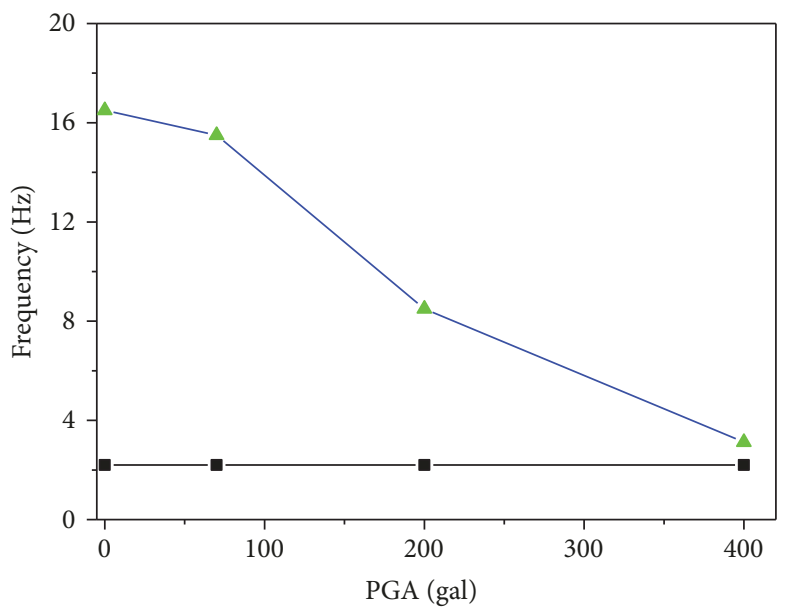

- - Specimen A (mode 1 )

- $\_$- Specimen B (mode 1 )

FIGURE 13: Frequency versus PGA.

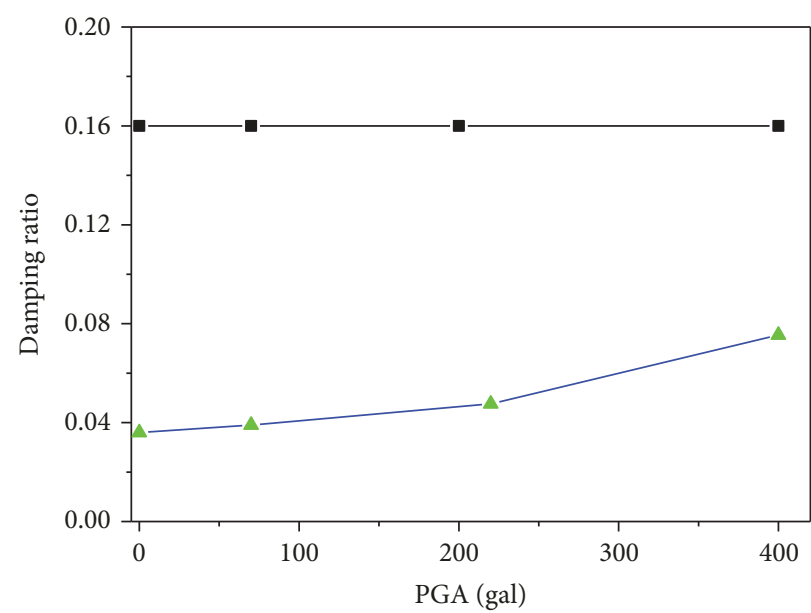

- - Specimen A (mode 1$)$

- - - Specimen B (mode 1)

FIGURE 14: Damping ratio versus PGA. 


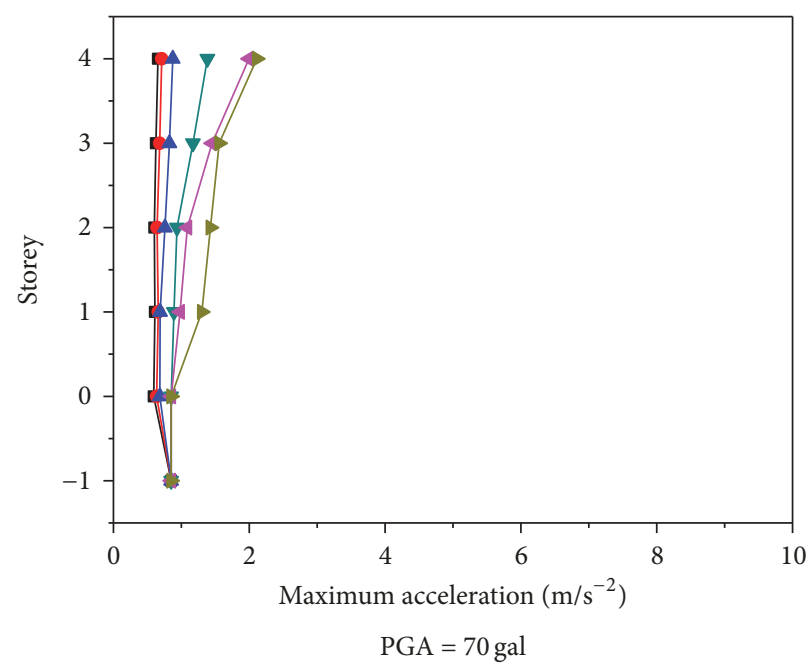

$\rightarrow$ Specimen A (TA1952) $\rightarrow-$ Specimen B (TA1952)
$\rightarrow$ Specimen A (AR2015) $\rightarrow$ Specimen B (AR2015)
$\rightarrow$ Specimen A (CA1968) $\rightarrow$ Specimen B (CA1968)

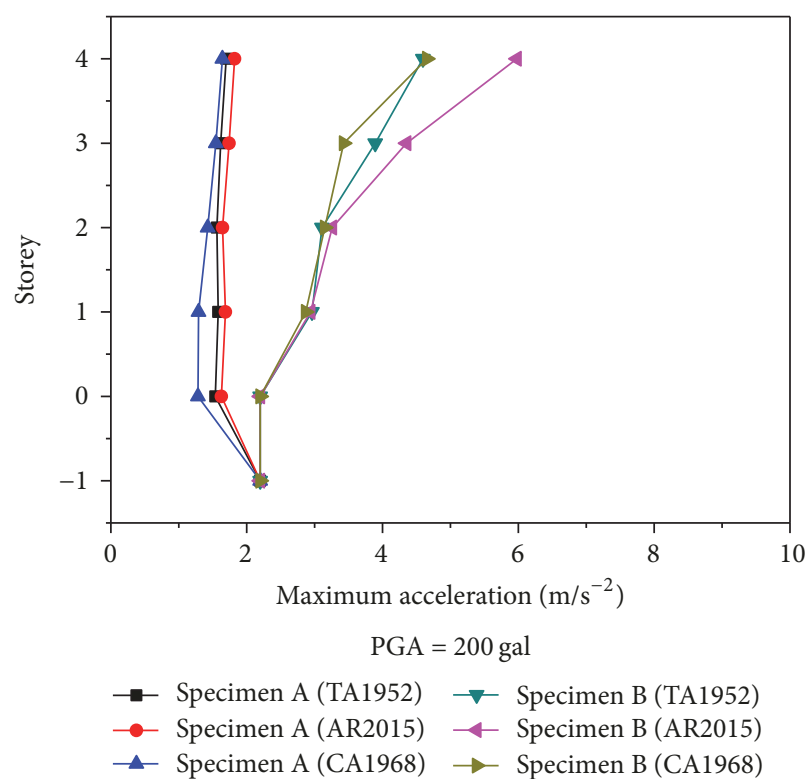

$\rightarrow$ Specimen A (AR2015) $\longleftarrow$ Specimen B (AR2015)

$\longrightarrow$ Specimen A (CA1968) $\rightarrow$ Specimen B (CA1968)

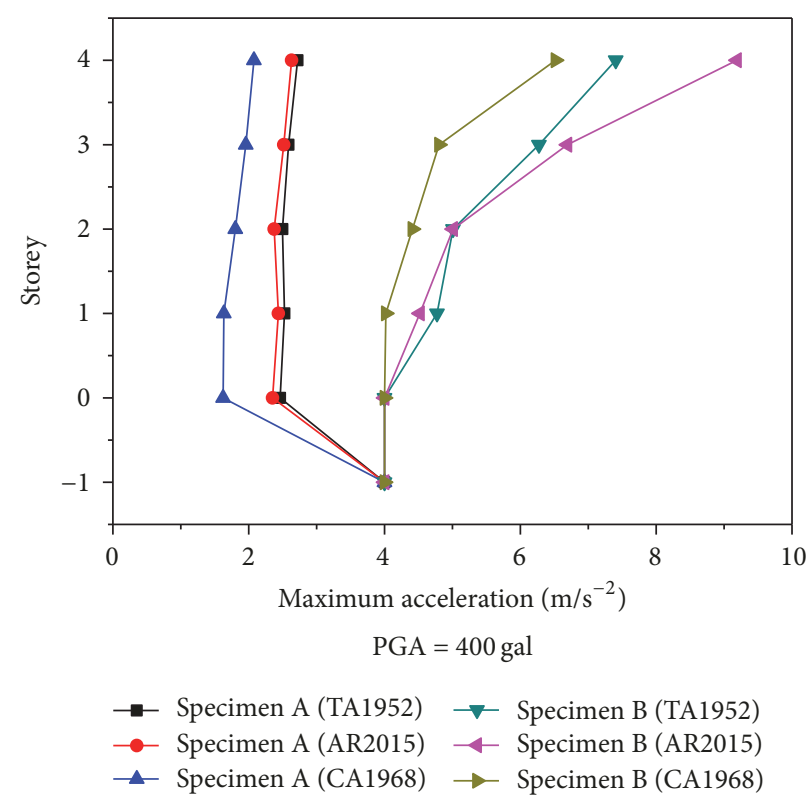

Figure 15: Acceleration.

the tests, there are no remarkable changes in the frequency and damping ratio of Specimen A. However, in the case of Specimen B, the frequency decreases and the damping ratio increases during the tests because of the cumulative damage in this specimen.

4.4. Acceleration Responses. The maximum storey acceleration of Specimens A and B is shown in Figure 15, and the maximum fourth-storey acceleration in all the test stages is displayed in Figure 16. It is clear that the maximum storey acceleration of both Specimens A and B increases when the input PGA increases. In addition, with increase in the input PGA, there is insignificant increase in the maximum storey acceleration of the superstructure of Specimen A; however, there is a significant increase in the maximum storey acceleration of Specimen B.

The equation for the acceleration reduction ratio $\psi_{A}$ of the base-isolated structure is as follows:

$$
\psi_{A}=\frac{\left(A_{F}-A_{I}\right)}{A_{F}},
$$

where $A_{F}$ is the maximum acceleration of the base-fixed structure and $A_{I}$ is the maximum acceleration of the baseisolated structure.

Figure 17 depicts the acceleration reduction ratios in the fourth storey of Specimen A. It can be seen that, with the increase in the input PGA from 70 gal to 400 gal, there 


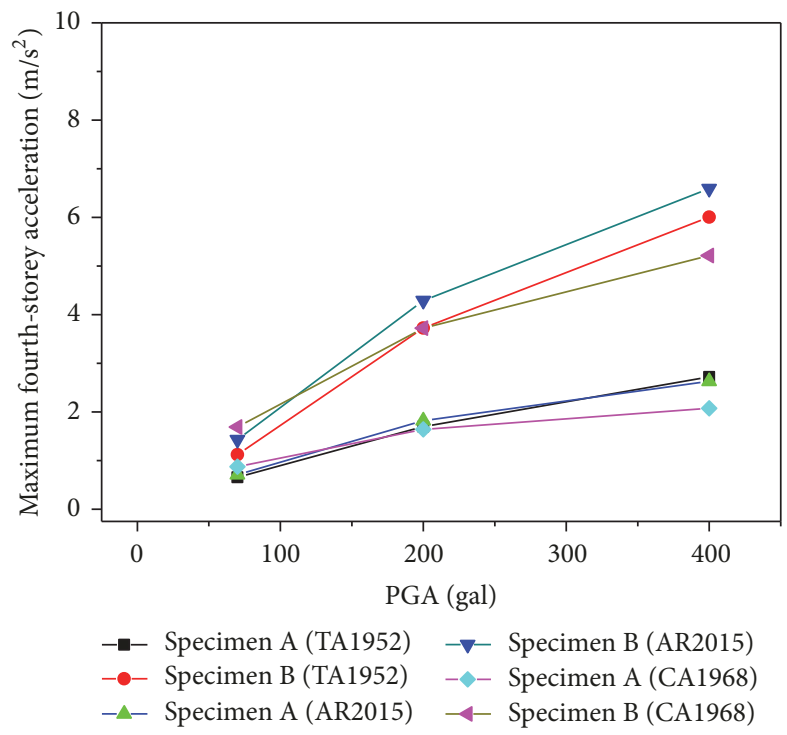

FIGURE 16: Maximum fourth-storey acceleration. Note. Storey number -1 represents the shaking table facility, and 0 represents the base beam.

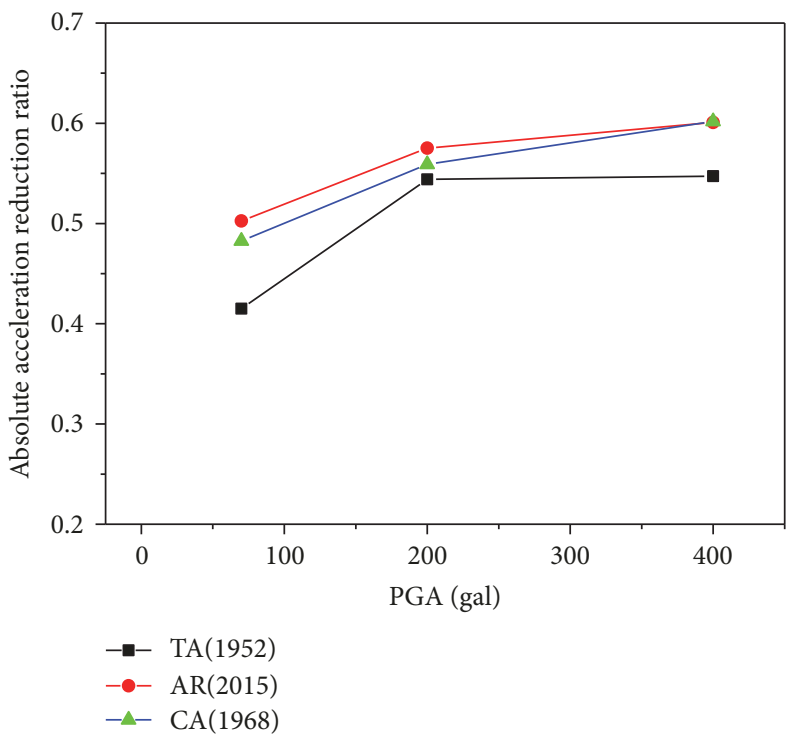

FIGURE 17: Fourth-storey acceleration reduction ratios. Note. Storey number -1 represents the shaking table facility, and 0 represents the base beam.

is an improvement in the reduction effect of acceleration responses. When the input PGA is $70 \mathrm{gal}$, the acceleration reduction ratio in the fourth storey is approximately $45 \%$, and when input PGA is $400 \mathrm{gal}$, the ratio increases to approximately 55\%. Compared to Specimen B, Specimen A with LRB base isolation system experienced significantly smaller acceleration. This auspicious response of Specimen A in terms of storey acceleration responses as compared to Specimen B is the result of the combined effect of a smaller equivalent lateral stiffness and a higher equivalent damping ratio of the LRBs.

4.5. Interstorey Drift (ISD) Responses. The ISD is closely related to structural damage. Figure 18 describes the maximum ISDs of Specimens A and B; Figures 19 and 20 depict the maximum ISDs in the fourth storey and the isolation storey in all the test stages, respectively. It is clear that the maximum ISDs of both specimens increase with the increase in the intensity of ground motion. Further, the maximum ISDs of Specimen A are less than those of Specimen B. For Specimen A, the ISDs in the base-isolated storey are much larger than those in the superstructure.

The equation for the ISD reduction ratio $\psi_{D}$ of the baseisolated structure is as follows:

$$
\psi_{D}=\frac{\left(D_{F}-D_{I}\right)}{D_{F}},
$$

where $D_{F}$ is the maximum ISD of the base-fixed structure and $D_{I}$ is the maximum ISD of the base-isolated structure. 

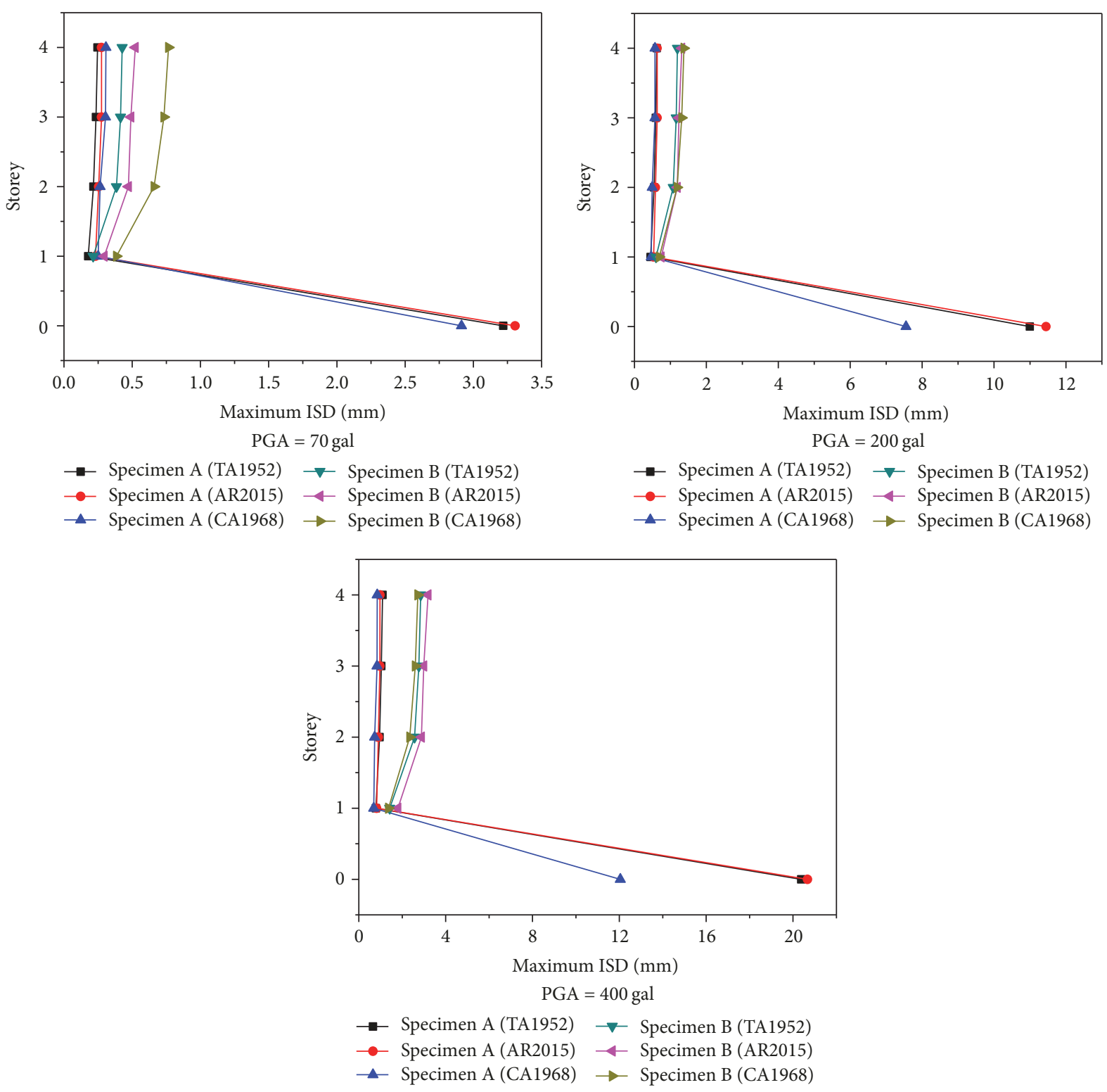

FIGURE 18: Maximum ISDs.

Figure 21 depicts the ISD reduction ratios in the fourth storey. It can be seen that the ISD reduction ratios increase with increase in the input PGA. When the input PGA is 70 gal, the ISD isolation ratio in the fourth storey is approximately $35 \%$, and when the input PGA is 400 gal, the ISD isolation ratio increases to approximately $60 \%$. The present LRB base isolation system reduces the ISDs to a great extent when subjected to ground motions with various PGA levels. This demonstrates the capability of the LRB base isolation system in protecting the PCSW structure against earthquakes.

4.6. Interstorey Shear Force (ISSF) Responses. Figure 22 shows the maximum ISSFs in Specimens A and B when subjected to ground motions with PGAs of 70 gal, 220 gal, and 400 gal. Figure 23 displays the maximum ISSFs of the first storey in the specimens in all the test stages. It can be seen that the maximum ISSFs in both specimens increase with the increase in the intensity of ground motions. The maximum ISSFs of Specimen A are less than those of Specimen B.

The equation for the ISSF reduction ratio $\psi_{V}$ of the baseisolated structure is as follows:

$$
\psi_{V}=\frac{\left(V_{F}-V_{I}\right)}{V_{F}},
$$

where $V_{F}$ is the ISSF of the base-fixed structure and $V_{I}$ is the ISSF of the base-isolated structure.

The ISSF reduction ratios of the first storey in Specimen A are shown in Figure 24. It can be observed that, with increase in the input PGA, the ISSF reduction ratios in the first storey increase. When the input PGA is 70 gal, the ISSF 


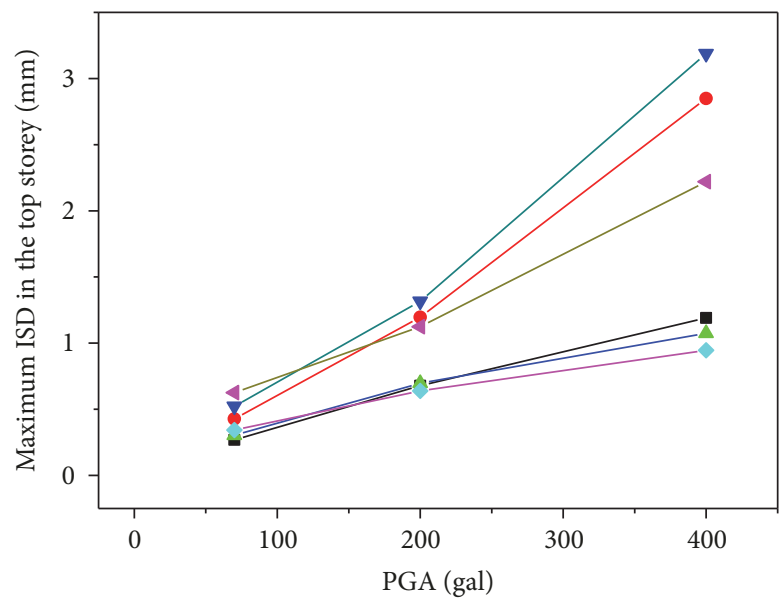

- - Specimen A (TA1952) - $\boldsymbol{\nabla}-$ Specimen B (AR2015)

- - Specimen B (TA1952) $\quad-\diamond-$ Specimen A (CA1968)

- - Specimen A (AR2015) - -4 Specimen B (CA1968)

FIGURE 19: Maximum ISDs in the fourth storey.

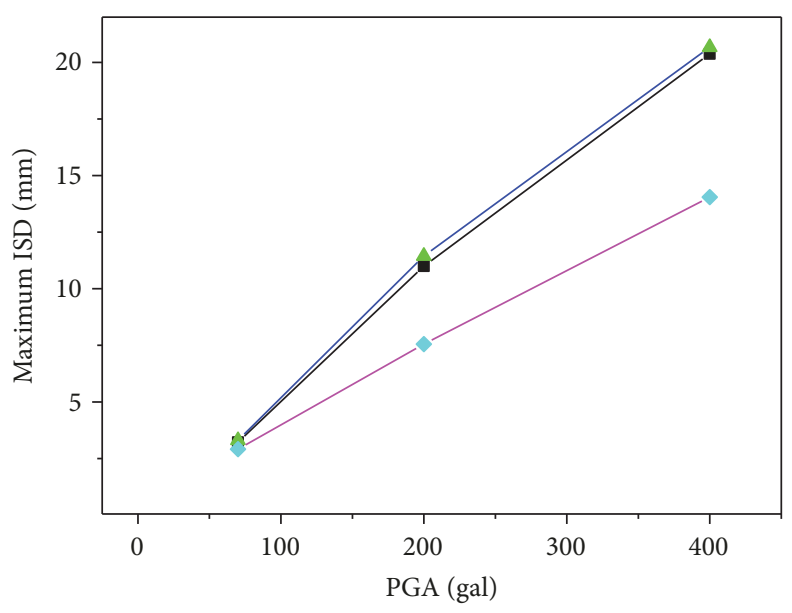

- - TA1952

-A- AR2015

$-\diamond-$ CA1968

FIgURE 20: Maximum ISDs in the isolation storey.

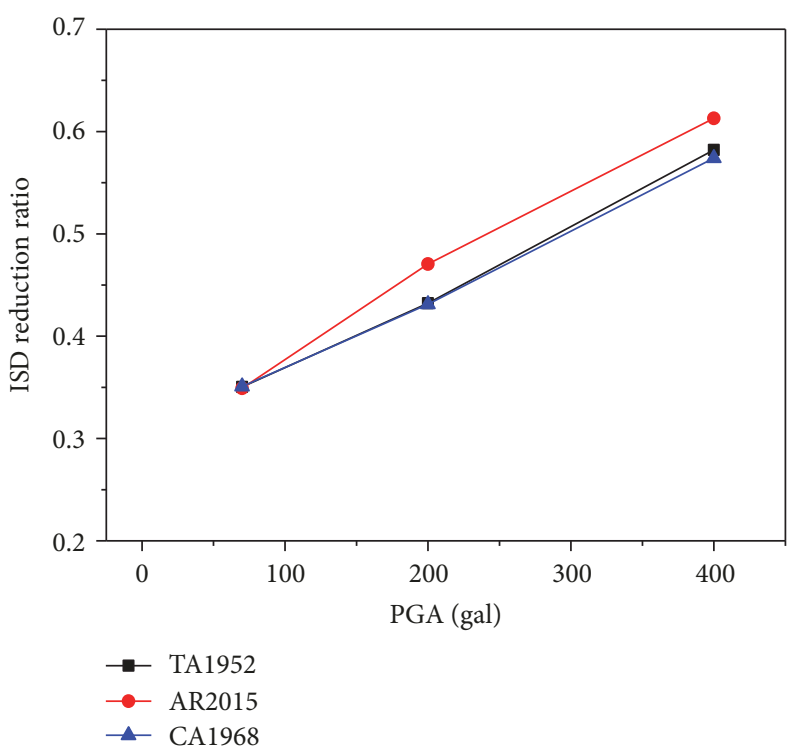

FIGURE 21: ISD reduction ratios in the fourth storey. 

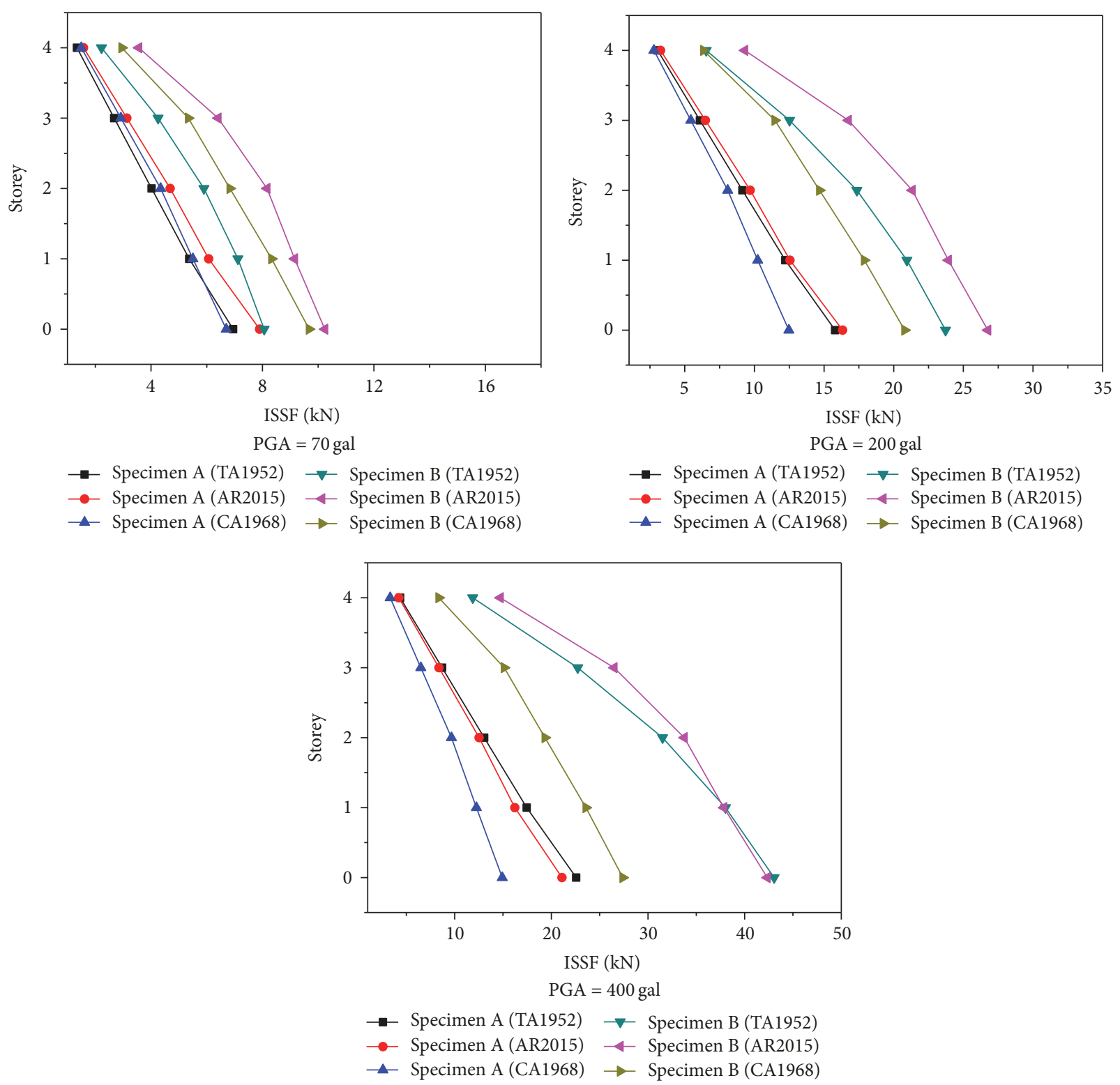

FIGURE 22: Maximum ISSFs.

reduction ratio in the first storey is approximately $25 \%$, and when the input PGAs are low, the ISSF reduction effect of the LRB is not significant. With increase in the input PGA, Specimen A exhibited better ISSF reduction capacity. When the input PGA is $400 \mathrm{gal}$, the ISSF reduction ratio of the first storey increases to approximately $50 \%$. In the case of a minor earthquake, the lateral stiffness of the LRB is relatively high, and the ISSF reduction effect is not significant. In the case of severe earthquakes, the equivalent lateral stiffness of the LRB decreases, and the ISSF reduction effect improves.

4.7. Energy Dissipation Property of Isolation Storey. Figure 25 shows the shear force-displacement hysteresis curves of the isolation storey in Specimen A, when subjected to input excitations with PGAs of 70 gal, 220 gal, and 400 gal. The dissipation energies of the isolation storey in all the test stages are shown in Figure 26. It can be seen that the shear force-displacement hysteresis curves of the isolation storey are spindle-shaped; this demonstrates the satisfactory energy dissipation property of the LRBs.

\section{Numerical Simulation}

The responses of the LRB base-isolated PCSW structure with improved AHW connections obtained during the tests were simulated using OpenSees software. As the improved AHW connection was in elastic state during the shaking table tests and there was no crack in the AHW connection area, it is assumed that mechanical performance of the improved AHW connection is akin to the equivalent cast-in-place connection and that the longitudinal rebars in the AHW connection region are continuous. 


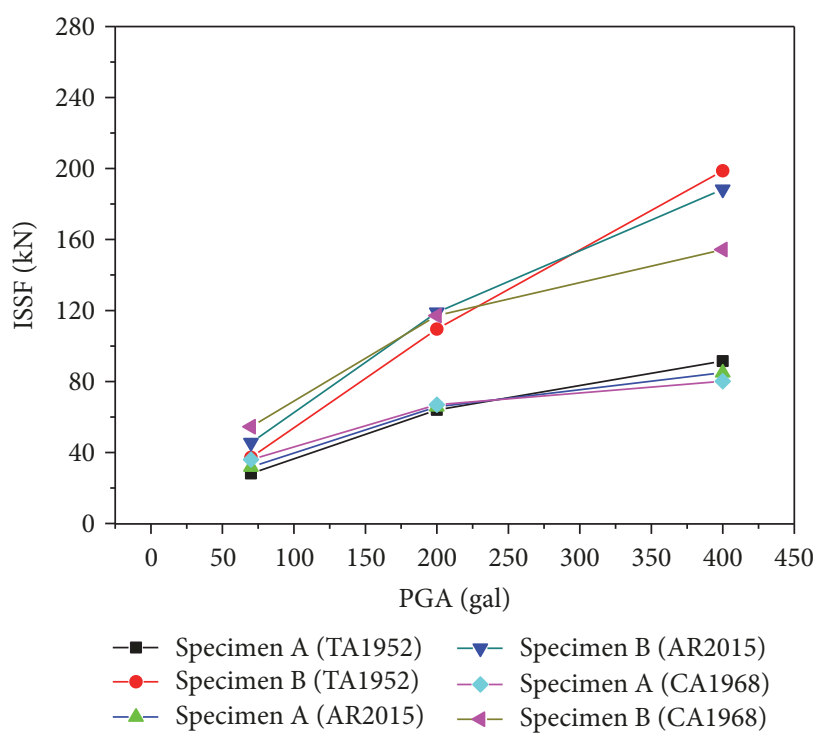

FIGURE 23: ISSFs of first storey.

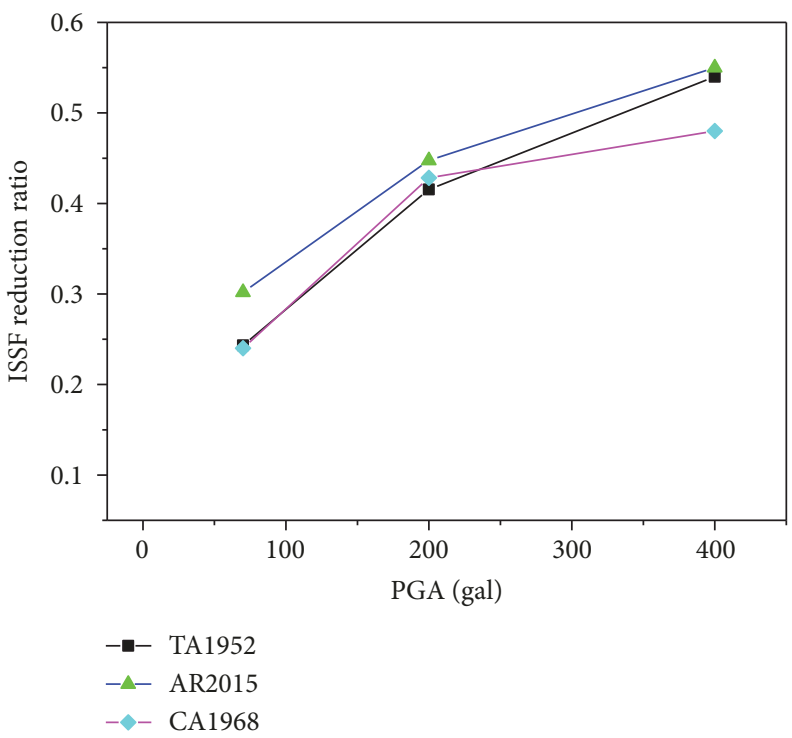

FIGURE 24: ISSF reduction ratios of first storey.

In the OpenSees modelling, the LRB was defined using the LeadRubberX element. The multilayer shell element was used to simulate the shear wall (refer http://www.luxinzheng.net). The concrete was divided into six layers, and the rebars were smeared into four layers. Point-mass model was used to simulate the added mass on each floor of the structures. The Rayleigh damping coefficient was taken as 0.05 to simulate the energy dissipation in the models.

The numerically simulated structural responses were compared with the test results, and the acceleration time history responses for the fourth storey of Specimen A, obtained from simulation and tests, are shown in Figure 27. It can be observed that the numerically simulated storey acceleration is close to the values obtained during the tests. The shear force-displacement hysteresis curves for the isolation storey of Specimen A, obtained from simulation and tests, are shown in Figure 28; the figure shows that the two curves match well. The results shown in Figures 27 and 28 indicate that the multilayer shell element and LeadRubberX element can be used to simulate the precast reinforced concrete shear wall and the LRB, respectively, and that the assumption of the longitudinal rebars in the AHW connection region being continuous is reasonable.

\section{Conclusions}

Shaking table tests and numerical simulation were performed to evaluate the seismic behaviour of a base-isolated PCSW structure model using improved AHW connections. During 

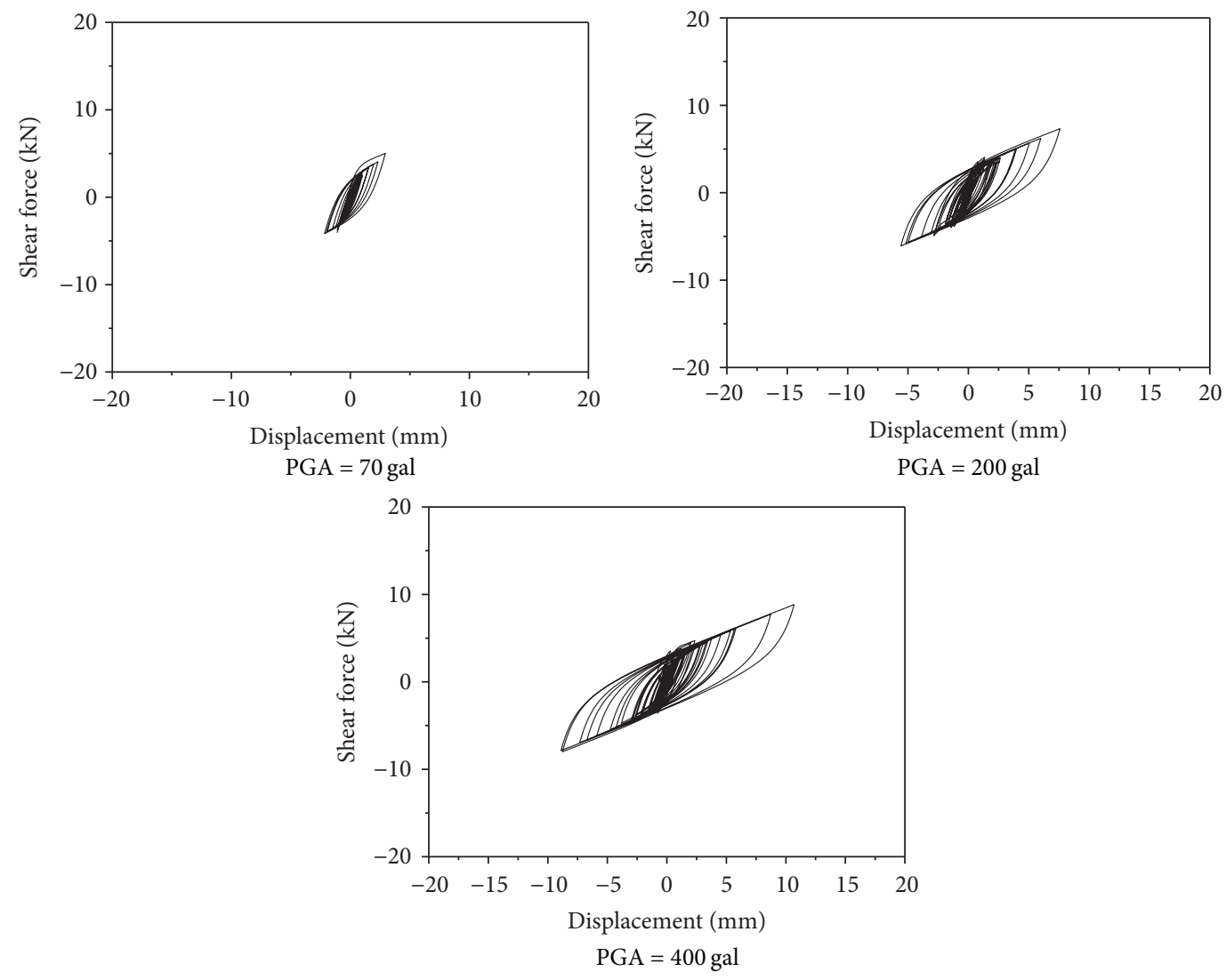

(a) CA1968
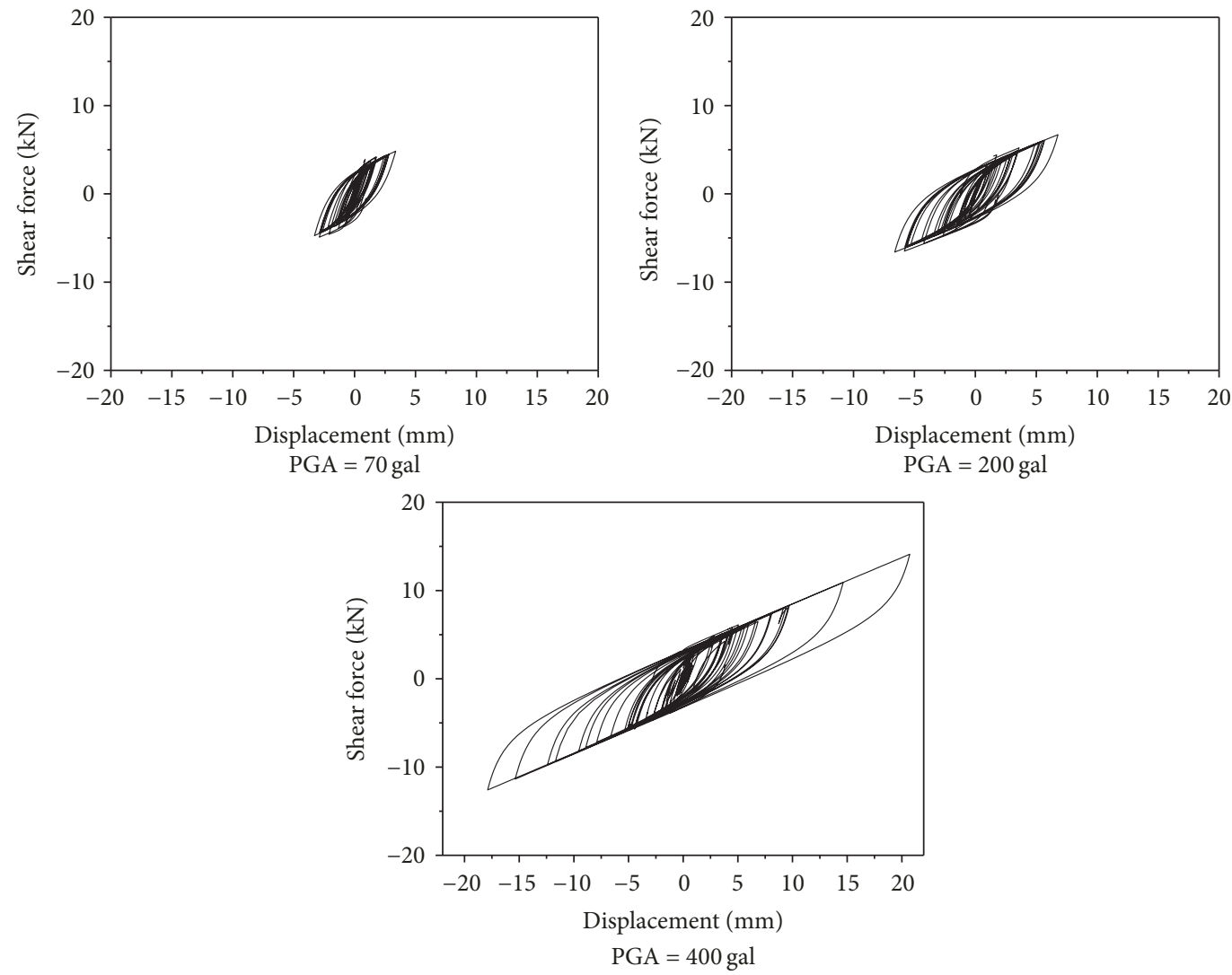

(b) AR2015

Figure 25: Continued. 

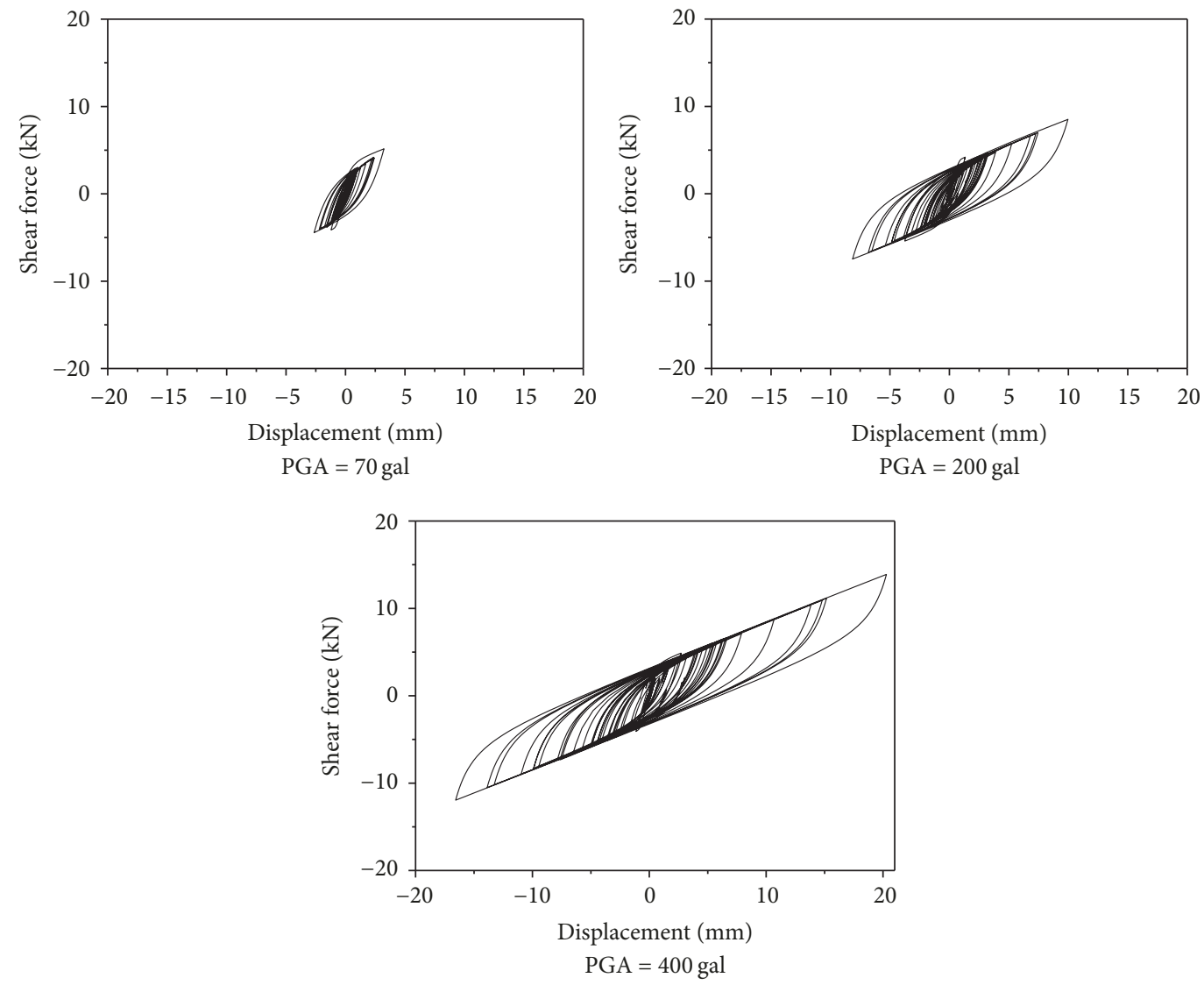

(c) TA1952

FIGURE 25: Shear force-displacement hysteresis curves of the isolation system.

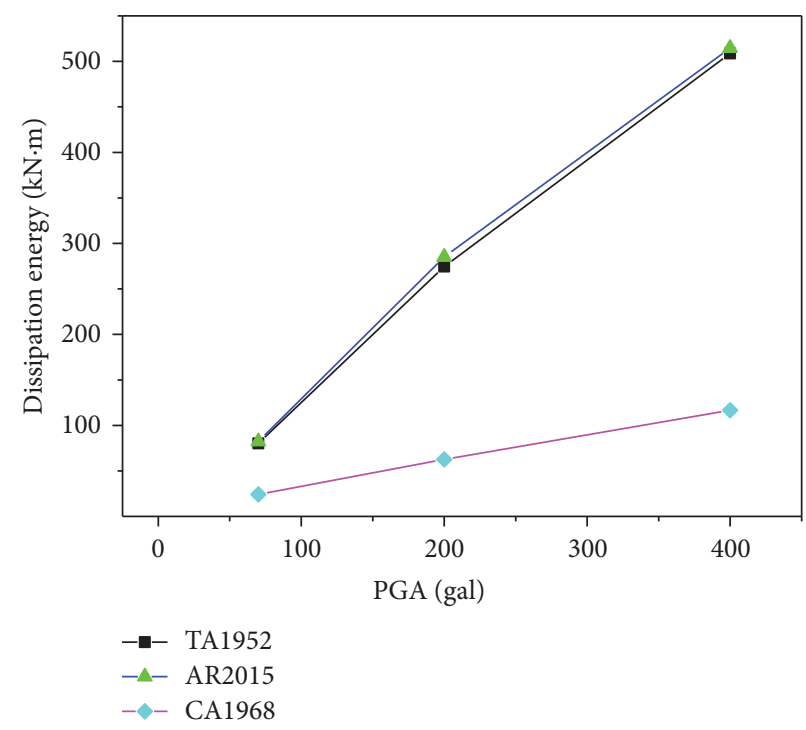

FIGURE 26: Dissipation energy of the isolation storey.

the tests, performance of the improved AHW connections was especially studied. The absolute acceleration responses and deformation responses of the base-isolated PCSW structure model were measured to reveal the dynamic properties and failure modes of the structure. Furthermore, OpenSees software was used to simulate the seismic response of the base-isolated PCSW structure model. Based on the results, conclusions are draw as follows. 


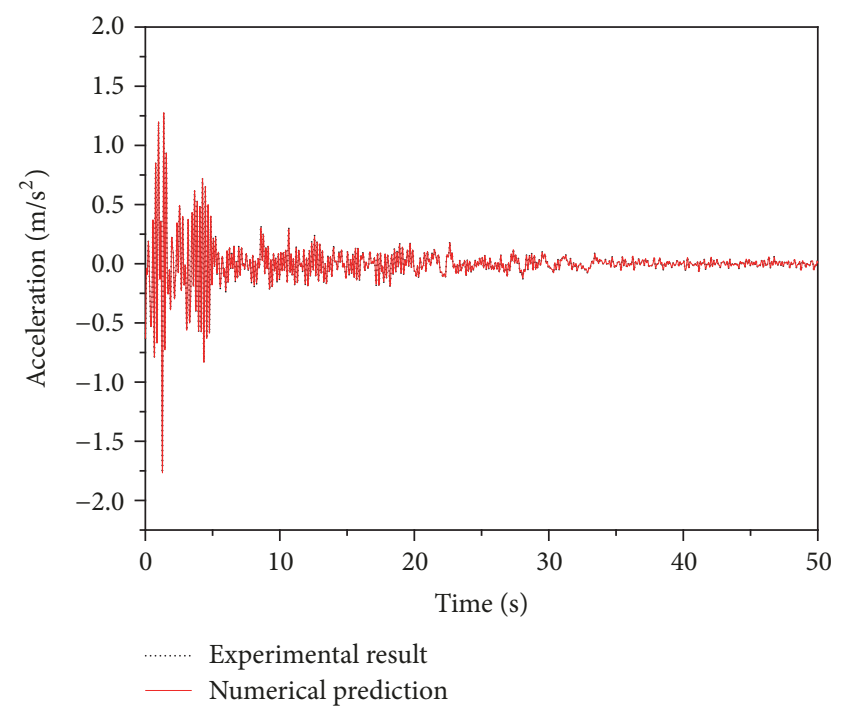

(a) CA1968

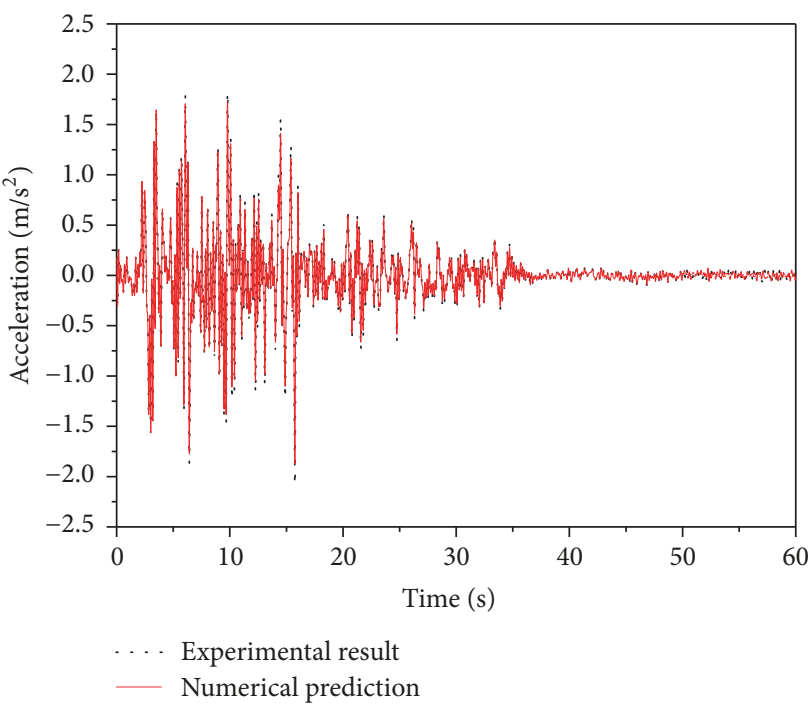

(b) TA1952

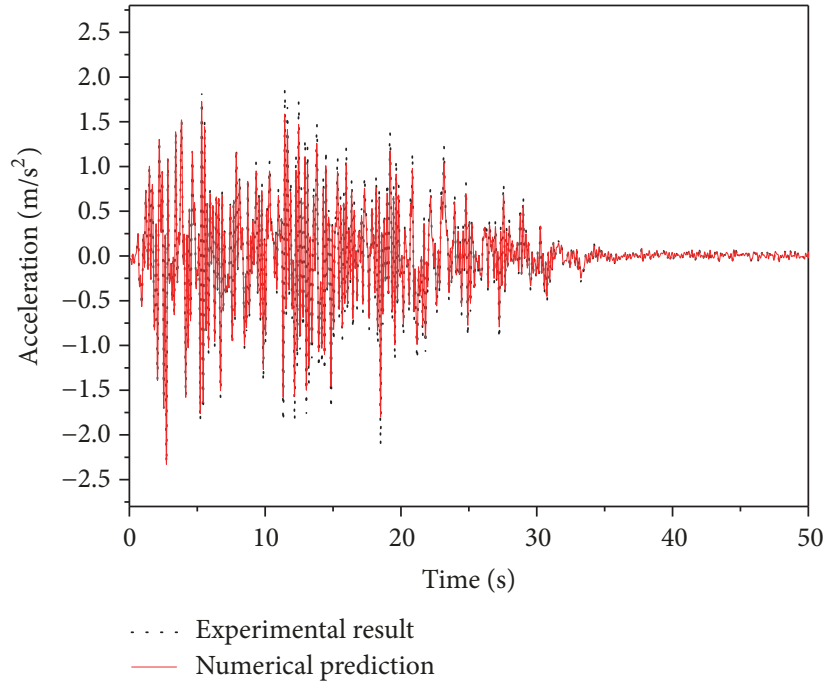

(c) AR2015

FIGURE 27: Comparison of acceleration history responses of the fourth storey for PGA $=400$ gal.

(1) There was no crack in the AHW connection area in the base-isolated PCSW structure model, indicating that the reliability of the improved AHW connection and the safety of the PCSW structure can be ensured during earthquakes.

(2) Compared with the base-fixed PCSW structure model, the base-isolated PCSW structure model had less cracks in the AHW connection area, coupling beams and shear walls, indicating that the LRB isolation system can reduce cracks effectively.

(3) The structural damping ratio can be increased to $16 \%$ by installation of LRBs, and the frequency of the structure can be reduced to $2.2 \mathrm{~Hz}$.

(4) The absolute acceleration response, ISD response, and maximum ISSF response of the PCSW structure model can be reduced significantly by the installation of LRBs. When the input PGA is 400 gal, the acceleration reduction ratio was approximately $55 \%$; the ISD isolation ratio was approximately $60 \%$; and the ISSF reduction ratio of the first storey was approximately $50 \%$.

(5) The seismic responses of the base-isolated PCSW structures with the improved AHW connections can be numerically simulated using OpenSees software, based on the assumptions that mechanical performance of the improved AHW connection is akin to the equivalent cast-in-place connection and that the longitudinal rebars in the AHW connection region are continuous.

\section{Conflicts of Interest}

The authors declare that they have no conflicts of interest. 


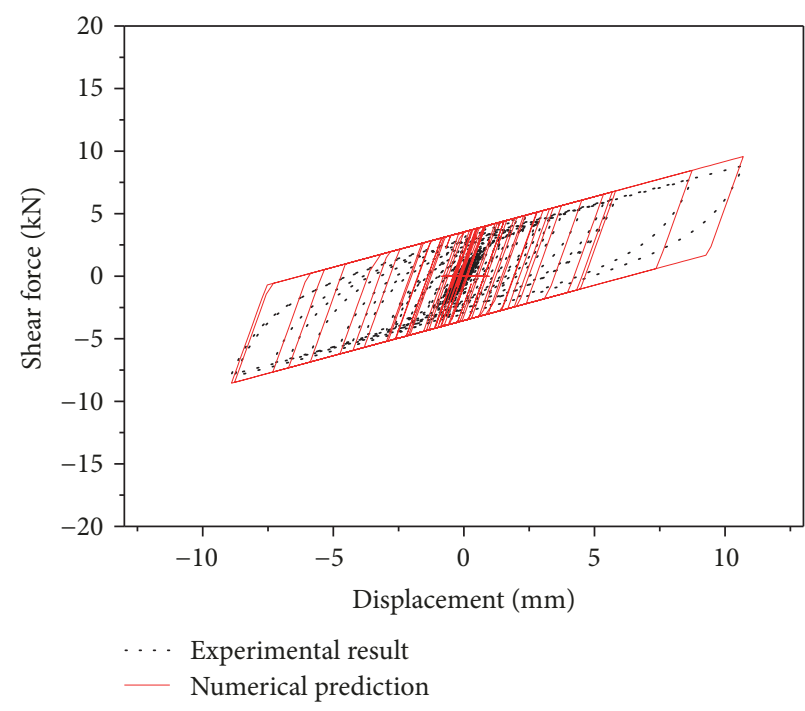

(a) CA1968

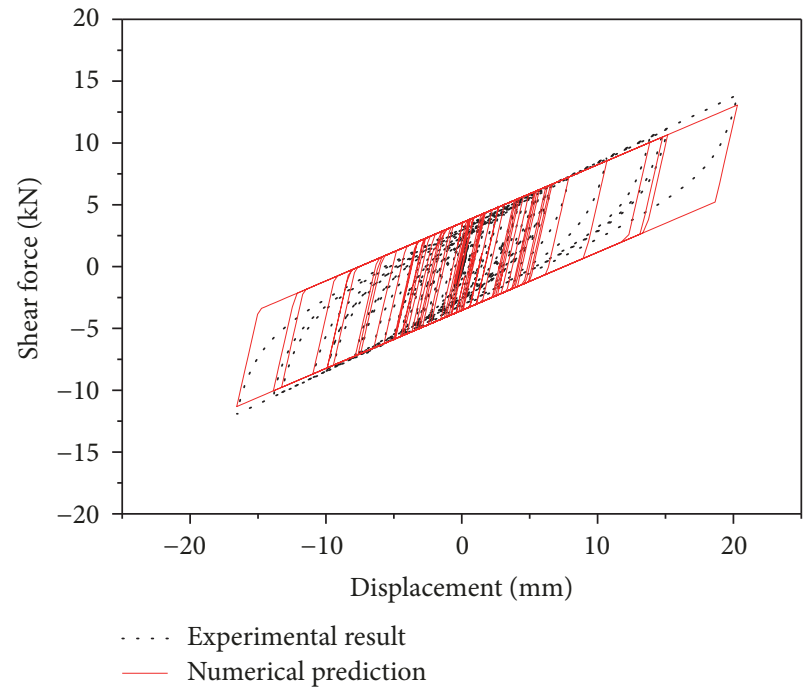

(b) TA 1952

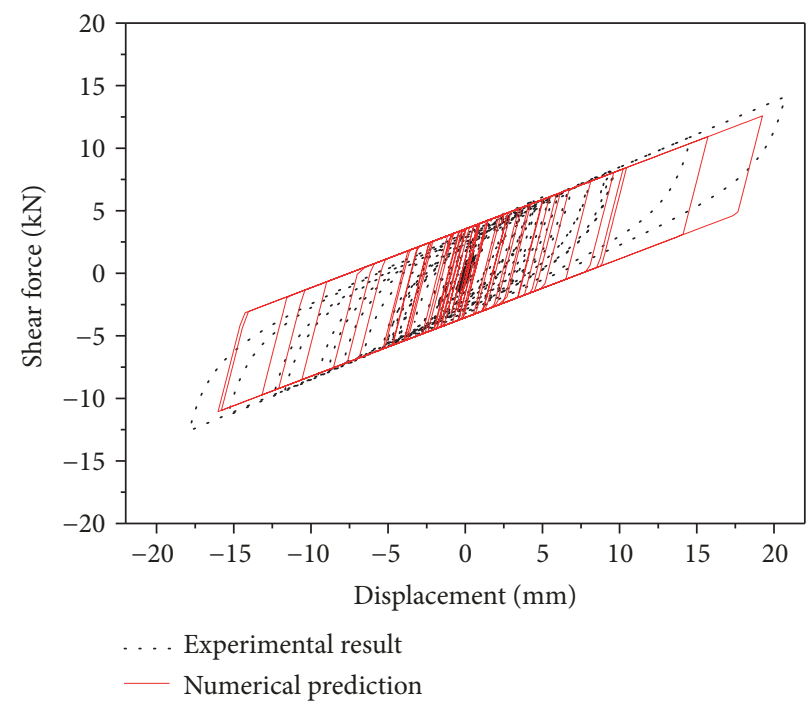

(c) AR2015

FIGURE 28: Comparison of shear force-displacement hysteresis loops of the isolation system for PGA = 400 gal.

\section{Acknowledgments}

The authors are grateful for the funding provided by National Key Research and Development Program of China (Grant No. 2017YFC0703602), the National Natural Science Foundation of China (Grants nos. 51708257 and 51708258), Natural Science Foundation for Colleges and Universities in Jiangsu Province (17KJB560002), and the Science Foundation of Jiangsu University of Science and Technology (Grant no. 1122931605).

\section{References}

[1] W. Wang, A. Li, and X. X. Wang, "Seismic performance of precast concrete shear wall structure with novel assembly horizontal wall connections," Bulletin of Earthquake Engineering, pp. 1-26, 2018.
[2] Y. Kurama, S. Pessiki, R. Sause, and L.-W. Lu, "Seismic behavior and design of unbonded post-tensioned precast concrete walls," PCI journal, vol. 44, no. 3, pp. 72-89, 1999.

[3] A. Belleri, M. J. Schoettler, J. I. Restrepo, and R. B. Fleischman, "Dynamic behavior of rocking and hybrid cantilever walls in a precast concrete building," ACI Structural Journal, vol. 111, no. 3, pp. 661-671, 2014.

[4] K. S. Elliott, Precast Concrete Structures, CRC Press, 2016.

[5] S. Gavridou, J. W. Wallace, T. Nagae, T. Matsumori, K. Tahara, and K. Fukuyama, "Shake-Table test of a full-scale 4-story precast concrete building. I: overview and experimental results," Journal of Structural Engineering (United States), vol. 143, no. 6, Article ID 04017034, 2017.

[6] S. Gavridou, J. W. Wallace, T. Nagae, T. Matsumori, K. Tahara, and K. Fukuyama, "Shake-table test of a full-scale 4-story precast concrete building. II: analytical studies," Journal of 
Structural Engineering (United States), vol. 143, no. 6, Article ID 04017035, 2017.

[7] J. Qian, X. Yang, H. Qin, Y. Peng, J. Zhang, and J. Li, “Tests on seismic behavior of pre-cast shear walls with various methods of vertical reinforcement splicing," Journal of Building Structures, vol. 32, no. 6, pp. 51-59, 2011 (Chinese).

[8] M. J. Ameli, J. E. Parks, D. N. Brown, and C. P. Pantelides, "Seismic evaluation of grouted splice sleeve connections for reinforced precast concrete column-to-cap beam joints in accelerated bridge construction," PCI journal, vol. 60, no. 2, pp. 80-103, 2015.

[9] A. Solak, Y. S. Tama, S. Yılmaz, and H. Kaplan, "Experimental study on behavior of anchored external shear wall panel connections," Bulletin of Earthquake Engineering, vol. 13, no. 10, pp. 3065-3081, 2015.

[10] F. J. Perez, R. Sause, and S. Pessiki, "Analytical and experimental lateral load behavior of unbonded posttensioned precast concrete walls," Journal of Structural Engineering, vol. 133, no. 11, pp. 1531-1540, 2007.

[11] F. J. Perez, S. Pessiki, and R. Sause, "Experimental lateral load response of unbonded post-tensioned precast concrete walls," ACI Structural Journal, vol. 110, no. 6, pp. 1045-1055, 2013.

[12] A. S. Pall, C. Marsh, and P. Fazio, "Friction joints for seismic control of large panel structures," PCI Journal, vol. 25, no. 6, pp. 38-61, 1980.

[13] O. A. Pekau and D. Hum, "Seismic response of friction jointed precast panel shear walls," PCI Journal, vol. 36, no. 2, pp. 56-71, 1991.

[14] E. Villalobos, D. Escolano-Margarit, A. L. Ramírez-Márquez, and S. Pujol, "Seismic response of reinforced concrete walls with lap splices," Bulletin of Earthquake Engineering, vol. 15, no. 5, pp. 1-22, 2016.

[15] C. Alhan and H. P. Gavin, "Reliability of base isolation for the protection of critical equipment from earthquake hazards," Engineering Structures, vol. 27, no. 9, pp. 1435-1449, 2005.

[16] X. K. Zou, Q. Wang, G. Li, and C. M. Chan, "Integrated reliability-based seismic drift design optimization of baseisolated concrete buildings," Journal of Structural Engineering, vol. 136, no. 10, pp. 1282-1295, 2010.

[17] C. Zhao and J. Chen, "Numerical simulation and investigation of the base isolated NPPC building under three-directional seismic loading," Nuclear Engineering and Design, vol. 265, pp. 484-496, 2013.

[18] Y.-M. Fang and J.-P. Pu, "Field tests and simulation of lion-head river bridge," Shock and Vibration, vol. 14, no. 3, pp. 181-228, 2005.

[19] P. Zhou, W. L. Li, W. Li, and Z. Shuai, "Reconstruction of input excitation acting on vibration isolation system," Shock and Vibration, vol. 2016, Article ID 2784380, 12 pages, 2016.

[20] H. Moeindarbari and T. Taghikhany, "Novel procedure for reliability-based cost optimization of seismically isolated structures for the protection of critical equipment: a case study using single curved surface sliders," Structural Control and Health Monitoring, no. 1, 2017.

[21] A. R. Bhuiyan and M. S. Alam, "Seismic performance assessment of highway bridges equipped with superelastic shape memory alloy-based laminated rubber isolation bearing," Engineering Structures, vol. 49, no. 4, pp. 396-407, 2013.

[22] A. B. M. S. Islam, S. I. Ahmad, M. Z. Jumaat, R. R. Hussain, M. A. Rahman, and K. M. U. Darain, "Efficient design in building construction with rubber bearing in medium risk seismicity:
Case study and assessment," Journal of Civil Engineering and Management, vol. 20, no. 5, pp. 621-631, 2014.

[23] M. Ohsaki, T. Miyamura, M. Kohiyama, T. Yamashita, M. Yamamoto, and N. Nakamura, "Finite-element analysis of laminated rubber bearing of building frame under seismic excitation," Earthquake Engineering \& Structural Dynamics, vol. 44, no. 11, pp. 1881-1898, 2015.

[24] G. Özdemir, "Formulations of equivalent linearization of leadrubber bearings for incorporating the effect of lead core heating," Earthquake Spectra, vol. 31, no. 1, pp. 317-337, 2015.

[25] D. Lee and M. C. Constantinou, "Further results on the heating of single and multi-core lead-rubber bearings and dampers," Bulletin of Earthquake Engineering, vol. 14, no. 4, pp. 999-1016, 2016.

[26] M. Ahmadipour and M. S. Alam, "Sensitivity analysis on mechanical characteristics of lead-core steel-reinforced elastomeric bearings under cyclic loading," Engineering Structures, vol. 140, no. 1, pp. 39-50, 2017.

[27] MHUCPRC, Code for Design of Concrete Structures (GB 500102010), Ministry of Housing and Urban-Rural Construction of the People's Republic of China, Beijing, China, 2010.

[28] MHUCPRC, Code for Seismic Design of Buildings (GB 500112010), Ministry of Housing and Urban-Rural Construction of the People's Republic of China, Beijing, China, 2010. 


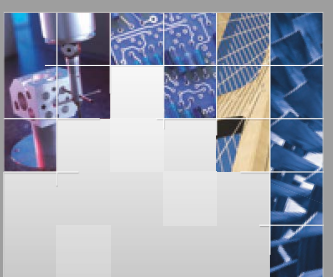

\section{Enfincering}
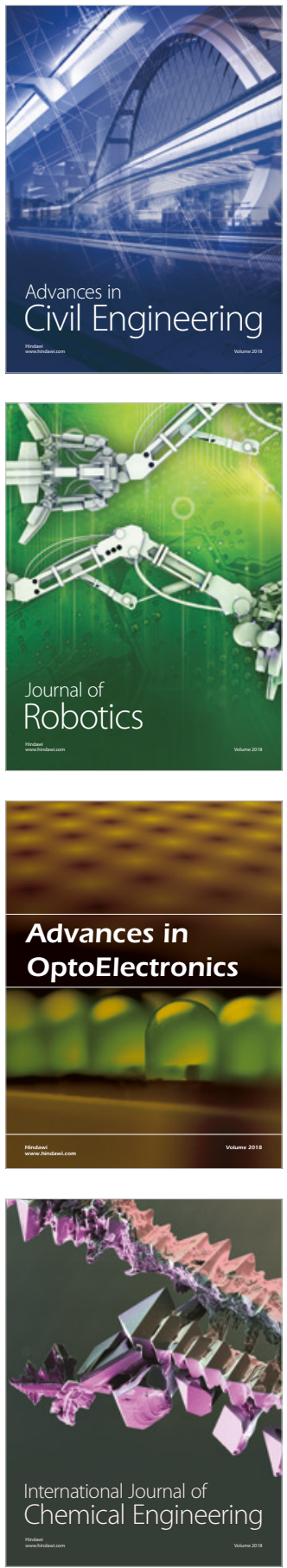

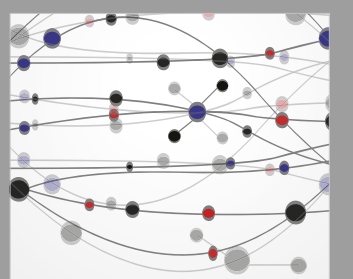

\section{Rotating \\ Machinery}

The Scientific World Journal

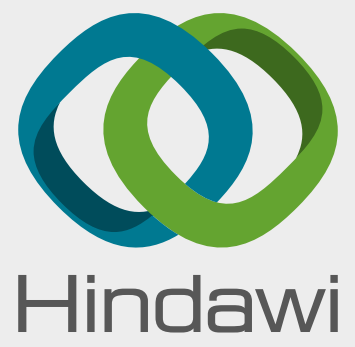

Submit your manuscripts at

www.hindawi.com
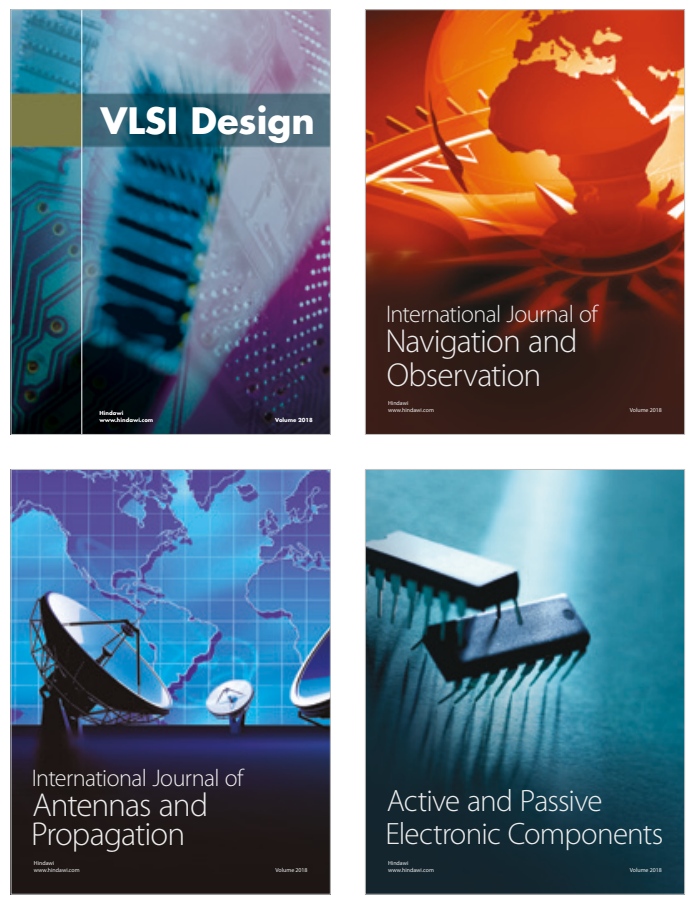
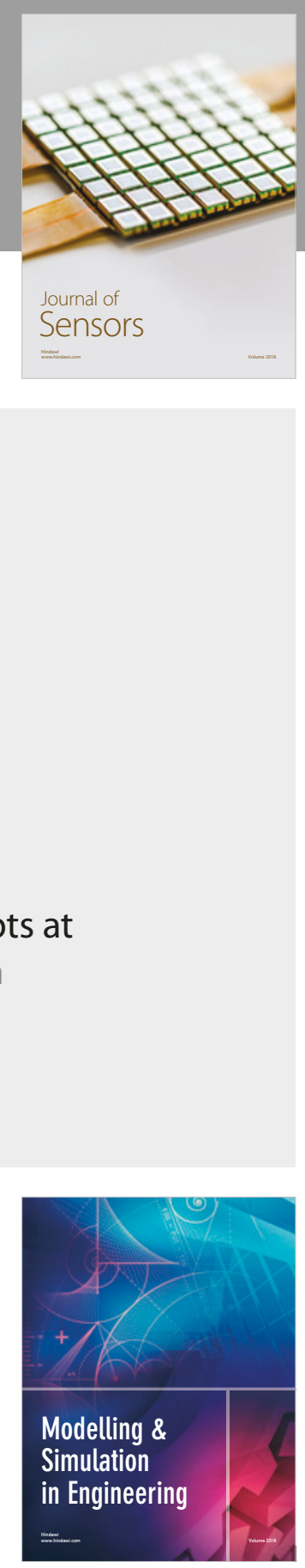

\section{Advances \\ Multimedia}
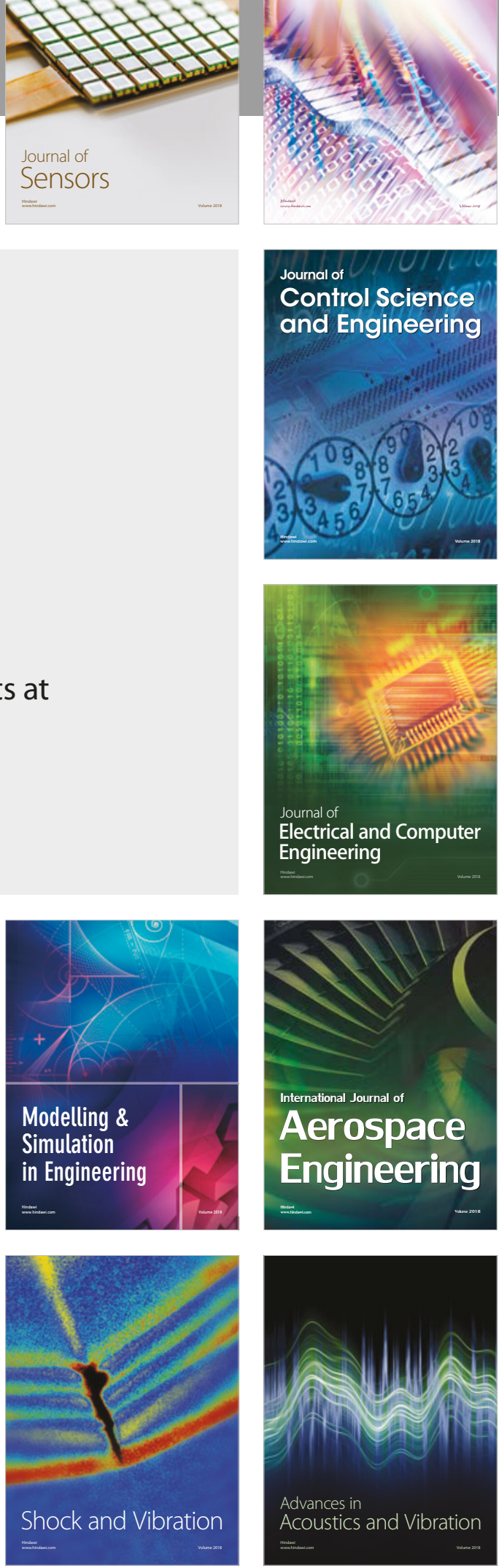